\title{
Muscarinic receptors mediate motivation via preparatory neural activity in humans
}

Grogan, John P. ${ }^{* 1}$, Raemaekers, Matthias ${ }^{2}$, Van Swieten, Maaike, M. H. ${ }^{1}$, Green, Alexander L. ${ }^{1}$, Gillies, Martin J. ${ }^{3}$, \& Manohar, Sanjay G. ${ }^{1}$.

1. Nuffield Department of Clinical Neuroscience, University of Oxford, UK

2. Department of Experimental, Clinical and Health Psychology, Ghent University, Belgium

3. Nuffield Department of Surgical Sciences, University of Oxford, UK

* Corresponding author. John.grogan@ndcn.ox.ac.uk

\section{Abstract}

10 Motivation depends on dopamine, but might be modulated by acetylcholine which influences dopamine release in the striatum, and amplifies motivation in animal studies. A corresponding effect in humans would be important clinically, since anticholinergic drugs are frequently used in Parkinson's disease, a condition that can also disrupt motivation. Reward and dopamine make us more ready to respond, as indexed by reaction times (RT), and move faster, sometimes termed

15 vigour. These effects may be controlled by preparatory processes that can be tracked using EEG. We measured vigour in a placebo-controlled, double-blinded study of trihexyphenidyl (THP), a muscarinic antagonist, with an incentivised eye movement task and EEG. Participants responded faster and with greater vigour when incentives were high, but THP blunted these motivation effects, suggesting that muscarinic receptors facilitate invigoration by reward. Preparatory EEG build-up

20 (contingent negative variation; CNV) was strengthened by high incentives and by muscarinic blockade. The amplitude of preparatory activity predicted both vigour and RT, although over distinct scalp regions. Frontal activity predicted vigour, whereas a larger, earlier, central component predicted RT. Indeed the incentivisation of RT was partly mediated by the CNV, though vigour was not. Moreover, the CNV mediated the drug's effect on dampening incentives, suggesting that

25 muscarinic receptors underlie the motivational influence on this preparatory activity. Taken together, these findings show that a muscarinic blocker used to treat Parkinson's disease impairs motivated action in healthy people, and that medial frontal preparatory neural activity mediates this for RT.

\section{Introduction}

Motivation is our ability to exert effort to obtain reward, and can be dramatically impacted in psychiatric and neurological disorders. One simple index of motivation is response vigour: an increase in movement speed with reward (Dudman \& Krakauer, 2016; Shadmehr, De Xivry, XuWilson, \& Shih, 2010). Motivation and the lack of motivation (apathy) have been linked to dopamine (McGuigan et al., 2019; Walton \& Bouret, 2019), and accordingly, vigour is reduced in Parkinson's disease (Beierholm et al., 2013; Da Silva, Tecuapetla, Paixão, \& Costa, 2018; Mazzoni, Hristova, \& Krakauer, 2007; Zénon, Devesse, \& Olivier, 2016). 
Striatal dopamine levels ramp up before potentially rewarding actions. Recent animal work demonstrates that acetylcholine controls these dopaminergic effects via firing rates (Forster \& Blaha, 2000; Mark, Shabani, Dobbs, \& Hansen, 2011), as well as local release (Cachope \& Cheer, 2014; Shen et al., 2007). These provide two mechanisms for acetylcholine to affect motivation (Collins et al., 2019; Hoebel, Avena, \& Rada, 2007), with muscarinic receptors in nucleus accumbens playing an important role in facilitating reward-related vigour (Collins, Aitken, Greenfield, Ostlund, \& Wassum, 2016), possibly by potentiating dopamine release and affecting the frequency-sensitivity of striatal

45 dopaminergic terminals (Collins et al., 2016; Threlfell et al., 2010). However, the ultimate effect of systemic muscarinic drugs on motivation is complex. Muscarinic antagonism has impaired motivation in some animal studies (Collins et al., 2016; Ostlund, Kosheleff, \& Maidment, 2014; Pratt \& Kelley, 2004), while improving it in others (Hailwood et al., 2019; Nunes, Randall, Podurgiel, Correa, \& Salamone, 2013), and even less is known of how they affect humans. Pro-cholinergic drugs

50 may ameliorate clinical apathy, a disabling symptom seen in around $50 \%$ of patients with Parkinson's disease (Devos et al., 2014; Fahed \& Steffens, 2021; Pagonabarraga, Kulisevsky, Strafella, \& Krack, 2015), yet cholinergic blockers are commonly used to treat the motor symptoms. Distinguishing the mechanisms by which acetylcholine receptors contribute to movement and motivation will be critical for selecting appropriate treatments in these patients.

55 Motivation influences action selection and movement invigoration based on the motivational state that is set up before the action. One potential mechanism of this may be preparatory activation of frontal premotor areas, which may be indexed on EEG by the contingent negative variation (CNV; Walter, Cooper, Aldridge, McCallum, \& Winter, 1964), a slow negative potential that appears between a warning stimulus and a prompt to act (Brunia, van Boxtel, \& Böcker, 2012). Early models of the CNV proposed that it reflected cholinergic activity, modulated by dopamine, noradrenaline and GABA (Timsit-Berthier, 1991). Supporting this, muscarinic antagonists were found to disrupt the CNV in rodents (Ebenezer, 1986; Papart, Ansseau, \& Timsit-Berthier, 1997; Pirch, Corbus, Rigdon, \& Lyness, 1986)(Papart et al., 1997). This anticipatory signal reflects preparatory activation of supplementary motor area and anterior cingulate, that can be amplified by reward signals from ventral striatum (Nagai et al., 2004; Plichta et al., 2013). As a marker of motivation, the CNV is of great clinical interest, being is decreased by depression (Ansseau, Machowski, Franck, \& TimsitBerthier, 1985) and PD (Ikeda et al., 1997), and conversely, increased by dopaminergic medications (Linssen et al., 2011). Accordingly, the CNV is strengthened by monetary incentives dependent on performance (Berchio, Rodrigues, Strasser, Michel, \& Sandi, 2019; Novak, Novak, Lynam, \& Foti, 2016; Novak \& Foti, 2015) and reward contingency (Frömer, Lin, Dean Wolf, Inzlicht, \& Shenhav, 2021). Changes in the CNV could therefore provide a mechanistic handle on the effect of drugs on motivation.

Here we ask whether blocking muscarinic receptors would reduce motivation and increase distractibility in humans, and further, whether this is mediated by preparatory activity in medial

75 frontal areas. To test this, we measured the CNV in healthy adults after administration of an M1r antimuscarinic acetylcholine antagonist (Trihexyphenidyl; THP) or placebo, while they performed an incentivised eye movement task. We used a task that independently measured action selection and energisation, which may involve different neural mechanisms. 


\section{Methods}

Design

We used a randomised, counterbalanced, double-blinded, placebo-controlled trial of Trihexyphenidyl (THP). Participants were tested twice, once on placebo, and once on THP, making this a within-subject study. Ethical approval was granted by the University of Oxford MSIDREC (R45265/RE001).

\section{Drugs}

Participants were administered $2 \mathrm{mg}$ THP or $200 \mathrm{mg}$ lactose pills, both encapsulated in a digestible shell, and labelled A and B by a colleague not involved in the study. Participants were randomised to receive either tablet $A$ or $B$ on their first session, and $B$ or $A$ on their second. The experimenters did not know whether $A$ or $B$ contained the drug until all data were collected and pre-processed. On arrival, we checked participants felt well, and administered the dose. Testing began 1.5-2 hours later.

\section{Participants}

Our sample size calculations suggested 27 participants would detect a 0.5 effect size with .05 sensitivity and .8 power. Due to the pandemic, we had to halt the study part-way, with 20 completed participants and 5 participants who had completed one session only. We only analysed the 20 completed participants, which achieved a post-hoc power of 0.7 . The mean age was 28.15 years (SD $=8.03$ years .

Participants read the information sheet, and gave written informed consent. Participants were screened for contraindications (e.g. cardiovascular disease, hypo/hypertension, cardiac arrhythmia, stroke, kidney/liver disease, psychiatric conditions, gastrointestinal haemorrhage, glaucoma, epilepsy, lactose hypersensitivity, porphyria) for the drug and placebo, and 1-lead ECG was taken to check for prolonged QTc interval of over $480 \mathrm{~ms}$. A medical doctor checked all this information before the participant was admitted to the study.

Task

105 To measure invigoration of saccades by incentives, we adapted an incentivised saccade task (Manohar \& Husain, 2015), where participants had to make speeded saccades to a low-salience target in exchange for money, while avoiding a high-salience distractor. The task was run in Matlab R2018b and Psychtoolbox-3 (Kleiner et al., 2007).

Participants saw three grey circles each with a black fixation-cross (Figure 1a) on a black screen (11 ${ }^{\circ}$ apart), and had to fixate on the one that turned pink after $500 \mathrm{~ms}$ (+0-100ms jitter) for $300 \mathrm{~ms}$. An audio incentive cue was played $200 \mathrm{~ms}$ after fixation, $1100 \mathrm{~ms}$ duration, of a voice saying ' $50 \mathrm{p}$ maximum' or ' $0 p$ maximum' to indicate the maximum money available on this trial. Fixation was checked again after this to ensure fixation (300ms $+100 \mathrm{~ms}$ wait), and then the black fixation-cross turned white. This was the preparation cue, which occurred $1500 \mathrm{~ms}$ before the target onset. Then, one of the other two circles dimmed, indicating it was the target, and on $50 \%$ of trials the other circle simultaneously brightened, as a salient distractor. Participants were rewarded a proportion of the incentive based on how quickly they looked at the target circle, with an adaptive reward rule that had an exponential fall-off depending on the average reaction time in the previous up to 20 trials. This kept the rewards received roughly constant over the task. If participants looked at the distractor, they would need to make a corrective eye movement to the target, which would slow the 
time to reach the target, and result in less reward. Once gaze reached the target, a feedback sound was played if a medium (10-30p) or large (>30p) reward was obtained, while the value of reward earned flashed in the centre of the target circle for $800 \mathrm{~ms}$. A $1100 \mathrm{~ms}(+0-100 \mathrm{~ms}$ jitter) rest period followed each trial, where participants were allowed to blink. The target on one trial became the fixation location for the next trial.

There were thus four trial types, with two maximum incentive levels (50p or $0 p$ ) and the presence or absence of a distractor. There were six of each trial in a block, giving 24 trials, and 20 blocks ( 480 trials in total; 120 per condition). Participants could pause as long as they liked between blocks, with a minimum 4-second break. The first trial of each block also had an extra 4-second rest period

130 before the trial began to ensure participants were settled and ready.

Participants were given 24 practice trials during the screening visit and before the main task on each main visit. These included an extra fixation check during the $1500 \mathrm{~ms}$ delay between the preparation cue and target onset, and if they moved their eye more than $1^{\circ}$ during this time, the trial was flagged for repetition and the experimenter asked them to maintain fixation better. This training improved

135 fixation during piloting.

In addition to this task, two other tasks were performed that are not reported in this paper, including a working memory task and a reversal learning task. We asked participants to rate how they felt on a visual analogue scale before and after the tasks, and participants also performed a proand anti-saccade task, and measurement of the pupillary light reflex.

140 Eye-tracking

We tracked participants' eyes with an EyeLink 2000 (SR Research) at 1000Hz. Participants were seated $75 \mathrm{~cm}$ from the screen, with their head on a chin-rest and forehead-rest. Nine-point calibration was performed at the start of the task, and one-point validation was done at the start of each block, with re-calibrations if necessary. Stimuli were shown on an ASUS VG248Qe3D screen $145(53 \times 30 \mathrm{~cm}, 1920 \times 1080$ pixels, $60 \mathrm{~Hz})$.

Saccades were parsed with standard criteria (velocity $>30^{\circ} \mathrm{s}^{-1}$, acceleration $>8000^{\circ} \mathrm{s}^{-2}$ ). We took the first saccade over $1^{\circ}$ in amplitude within $100-900 \mathrm{~ms}$ after the target onset, and calculated velocity with a sliding window of $4 \mathrm{~ms}$, excluding segments faster than $3000^{\circ} \mathrm{s}^{-1}$ or where eye-tracking was lost. Saccades with peak velocities outside $50-1600^{\circ} \mathrm{s}^{-1}$ were excluded. Saccadic velocity is correlated 150 with the amplitude of the saccade, an effect known as the main sequence (Bahill, Clark, \& Stark, 1975), and saccade amplitude can also be affected by reward (Grogan, Sandhu, Hu, \& Manohar, 2020). To remove the effect of amplitude on velocity, we regressed peak velocity against amplitude within each participant and session, and took the residual peak velocity as our main measure (Figure 1c). This reflects the difference between the velocity measured and the velocity predicted by the

155 main sequence, with positive values meaning faster than expected velocity. This measure has previously been shown to be most sensitive to reward manipulations of vigour (Blundell et al., 2018; Grogan et al., 2020; Manohar, Finzi, Drew, \& Husain, 2017; Manohar, Muhammed, Fallon, \& Husain, 2019).

Saccadic reaction time (RT) was taken as the time between target onset and the start of the saccade (as detected by EyeLink; Figure 1b) in ms; we used log RT for the analyses but plot raw RT. Distractor pull was measured as the angular deviation of the eye from a straight line linking the fixation and target circles (Figure 2a) when it left the fixation circle; positive values reflected a bias towards the distractor, while negative values reflected a bias away from the distractor. These were analysed using linear mixed effects models, after z-scoring all factors and variables. 


\section{EEG acquisition and pre-processing}

We recorded EEG with a Refa72 amplifier (TMSi, B.v Netherlands) at $1024 \mathrm{~Hz}$ and using OpenVibe software (Renard et al., 2010). We used a 64-channel cap (TMSi). The ground was placed on the left clavicle, and we recorded horizontal EOG with bipolar electrodes placed either side of the eyes. Due to the cap, we could not place an EOG electrode above the eye, so one was placed $1 \mathrm{~cm}$ under the

170 left eye, and this was converted into a bipolar EOG signal as the difference from electrode FP1, which was the closest cap electrode to the left eye. Impedances were kept below $10 \mathrm{~K} \Omega$ as it was a high-impedance system.

Data were processed with custom Matlab scripts, and EEGLab and ERPLab toolboxes (Delorme \& Makeig, 2004; Lopez-Calderon \& Luck, 2014). Channels were referenced to the average of the two

175 mastoid electrodes $\mathrm{A} 1+\mathrm{A} 2$, and synchronised with the eye-tracking traces using the EYE-EEG toolbox (Dimigen, Sommer, Hohlfeld, Jacobs, \& Kliegl, 2011). Data were band-pass filtered at 0.1$80 \mathrm{~Hz}$ with an IIR Butterworth filter, notch filtered at $50 \mathrm{~Hz}$ with a stop-band Parks-McClellan filter, and down-sampled to $256 \mathrm{~Hz}$.

Epochs were from -200:1500ms around the preparation cue onset, and were baselined to the $100 \mathrm{~ms}$

180 before the preparation cue appeared. We rejected trials where participants blinked or made saccades (according to EyeLink criteria above) during the epoch, or where EEG voltage was outside 200:200 $\mu \mathrm{V}$ (muscle activity). On average 104/120 trials per condition per person were included (SD = 21). A repeated-measures ANOVA found there were no significant differences in number of trials excluded for any condition ( $p>.2)$.

185 We took the late CNV period (1200:1500ms) at electrode Cz as our a priori region of interest, along with the cue-P3 (200-280ms). We also performed cluster-based permutation testing using the DMGroppe Mass Univariate toolbox (Groppe, Urbach, \& Kutas, 2011) to look for other effects of incentive and THP across all channels and time-points in the epoch, and used linear mixed effects regression to determine which EEG measures predicted behaviour.

190 In order to see whether our results were specific to preparatory activity, we looked at activity before the preparation cue began, and looked at the late ERP to the incentive cue. We epoched the data from -200:1100ms around the incentive cue onset (which was the duration of the incentive cue), and used the same artefact rejection criteria as above.

\section{Data and code availability}

195 Anonymous data are available on OSF (https://osf.io/zuq5c/), and analysis code is on GitHub (https://doi.org/10.5281/zenodo.5141792).

\section{Results}

\section{Acetylcholine modulates invigoration by incentives}

Residual peak velocity of saccades, our measure of vigour, was increased by incentives (Figure 1d; $\beta$ $=0.1266, p<.0001)$, while distractors slightly slowed velocity $(\beta=-0.0158, p=.0294$; see Table S1 for full behavioural statistics), as predicted. THP reduced the invigoration of velocity by incentives (incentive ${ }^{*}$ THP: $\beta=-0.0216, p=.0030$ ), indicating that muscarinic blockade diminished motivation by incentives. There was no drug main effect or other significant interactions ( $p>.05$; see Table S1). Separate two-way analyses indicated this was driven mainly by trials when the distractor was absent (incentive*THP when distractors were: absent $\beta=-.0268, p=.0071$; present $\beta=-.0164, p=.1224$ ), 
bioRxiv preprint doi: https://doi.org/10.1101/2021.07.28.454154; this version posted July 29,2021 . The copyright holder for this preprin (which was not certified by peer review) is the author/funder, who has granted bioRxiv a license to display the preprint in perpetuity. It is made available under aCC-BY 4.0 International license.

although effects were in the same direction, and the three-way interaction was not significant $(p>$ $.05)$, suggesting that the distractor-present trials had the same effect but weaker.

a)

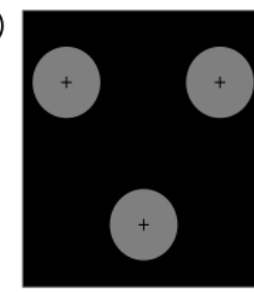

$500-600 \mathrm{~ms}$

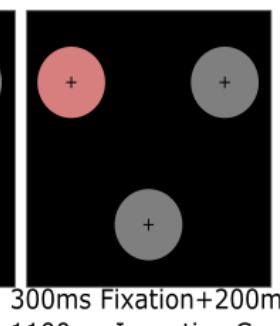

$1100 \mathrm{~ms}$ Incentive Cue

$300 \mathrm{~ms}$ Fixation $+100 \mathrm{~ms}$
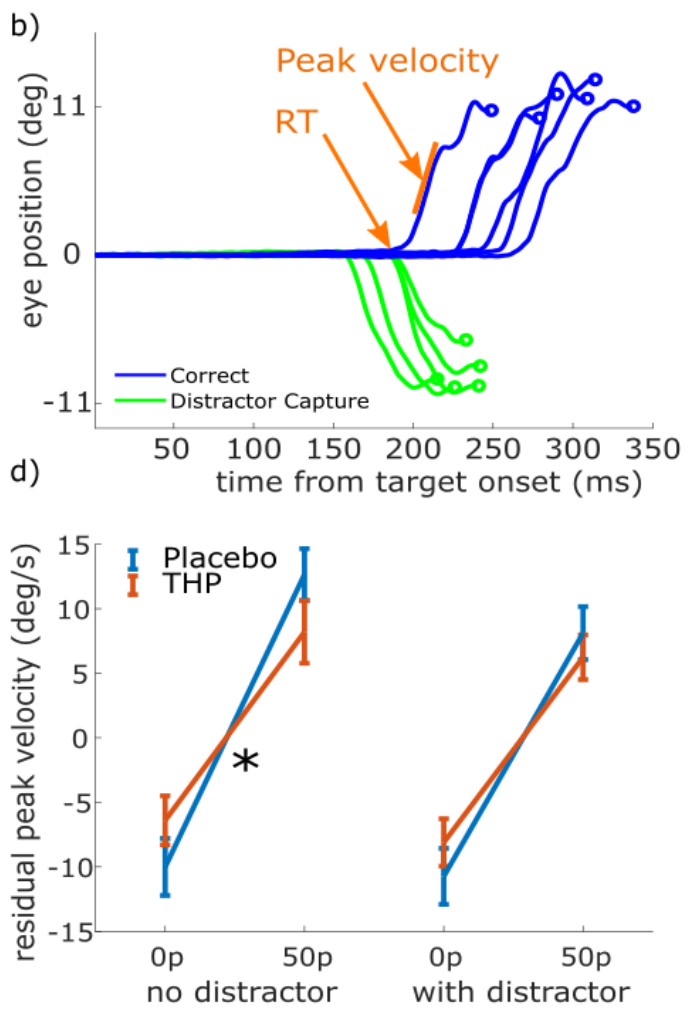

Time

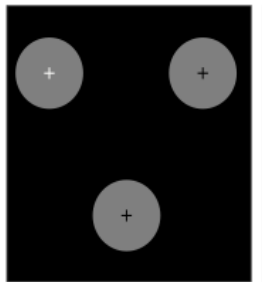

$1500 \mathrm{~ms}$

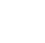

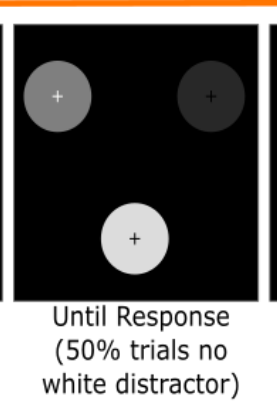

c) $\overparen{(n}$
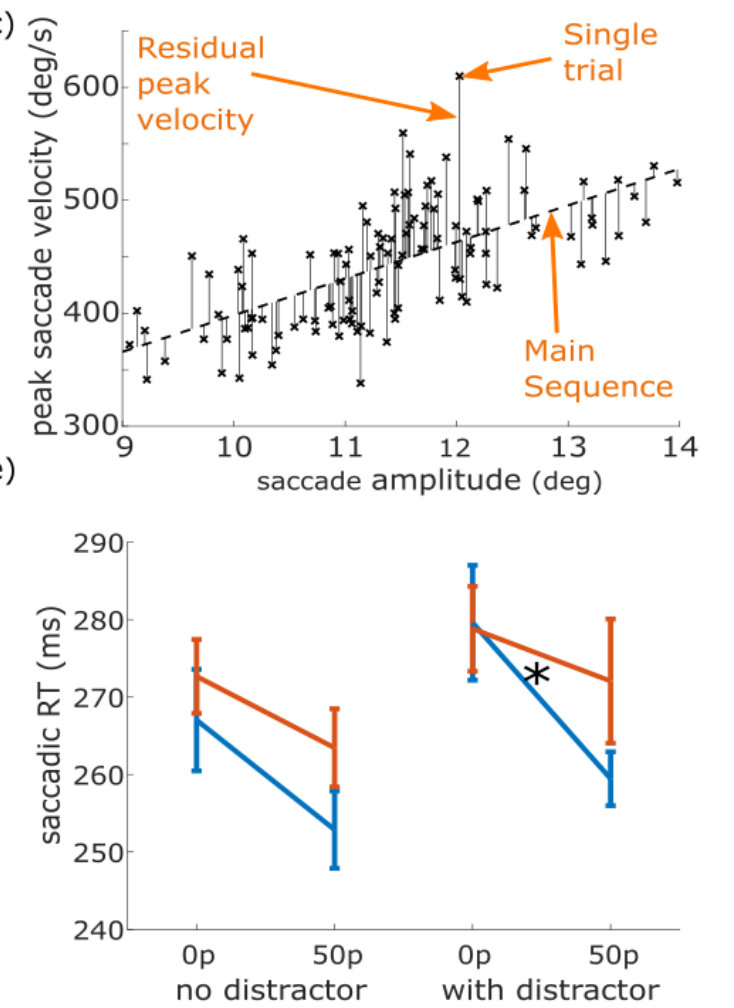

Figure 1. THP modulates saccadic measures. a) Trial structure for a high-incentive trial with a salient distractor. After fixation on the pink starting circle, the incentive cue plays, and after a short fixation wait the preparation cue is given which is the fixation cross turning white. 1500ms later, one circle dims, which is the target, and on 50\% of trials the other circle brightens (salient distractor). Feedback is given when participants saccade to the target, based on their speed. Timings are given below each screen. b) Eye position as a function of time for a selection of saccades. Saccade reaction time (RT) is the time at which the saccade begins, peak velocity is the maximal speed during the movement (steepest slope here), and amplitude is the distance to the saccade endpoint. c) Plotting peak velocity against amplitude shows the main sequence effect (dashed line) where larger saccades have higher velocity. We regressed velocity on amplitude to remove this, giving residual peak velocity as our measure of vigour (solid vertical lines). d) Mean peak residual velocity for each condition. Incentives increased velocity, distractors decreased it, and THP reduced the invigoration by incentives. This interaction was seen only for the no-distractor trials. e) Mean saccadic RT for each condition (log RT was analysed, raw values plotted here). High incentives decreased $R T$, distractors slowed $R T$, and THP reduced the effect of incentive on $R T$ - which was driven by trials with distractors present.

Log RT was also sped by incentives (Figure 1e; $\beta=-0.0767, p<.0001$ ), slowed by distractors ( $\beta=$ $0.0358, p<.0001)$, and slowed by THP $(\beta=0.0244, p=<.0001)$. Again, THP reduced the effects of incentives (incentive*THP: $\beta=0.0218, p=.0002$ ). Separate two-way analyses showed that this was 
225 driven by trials where the distractor was present (incentive*THP $\beta=.0293, p=.0006$ ), while this was not significant when distractors were absent $(\beta=.0143, p=.0819)$ - although as the three-way interaction was not significant and the direction of effects was the same in the two, it suggests that distractors may simply have weakened this effect slightly.

\section{Cholinergic blockade increases distractibility}

230 We measured distractibility as the angular deviation of the eye position away from the target's orientation towards the distractor's location, at the start of the saccade, (Figure 2a), which indicates the pull of the distractor. The distribution of distractor pull is bimodal, with saccades directed towards either the target or distractor locations (Figure 2c). Distractors pulled the eyes when they lit up, with repulsion when they did not (Figure $2 \mathbf{b} ; \beta=0.2446, p<.0001$ ). THP increased the pull (main

235 effect of drug, $\beta=0.0283, p<.0001$ ), but only when the distractor was salient (THP*distractor, $\beta=$ $0.0226, p=.0012$, pairwise drug effect: distractor absent: $p>.3$; present: $\beta=.0511, p<.0001)$. Unlike in previous work, we found no effect of incentives on distraction ( $\beta=.0023, p=.7444)$, although speed-accuracy trade-off curves (Figure S3) showed that incentives sped up responses in such a way that distraction was reduced for a given RT.

240 The drug-related increase in distraction could be due to either greater pull or reduced repulsion. To distinguish these possibilities, we plot the distribution of distractor pull across trials where the distractor was present (Figure $\mathbf{2 c}$ ). THP reduced the probability of repulsion (Figure $\mathbf{2 d}$ ) around $\mathbf{- 3 0 ^ { \circ }}$, indicating that THP reduced the repulsion away from the distractor's location. This could suggest weaker attentional suppression. Incentives had little effect on the distribution (yellow line) in

245 keeping with the averages in Figure $\mathbf{2 b}$.

Therefore, acetylcholine antagonism reduced the invigoration of saccades by incentives, and increased the pull of salient distractors. We next asked whether these effects were coupled with changes in preparatory neural activity. 
a)
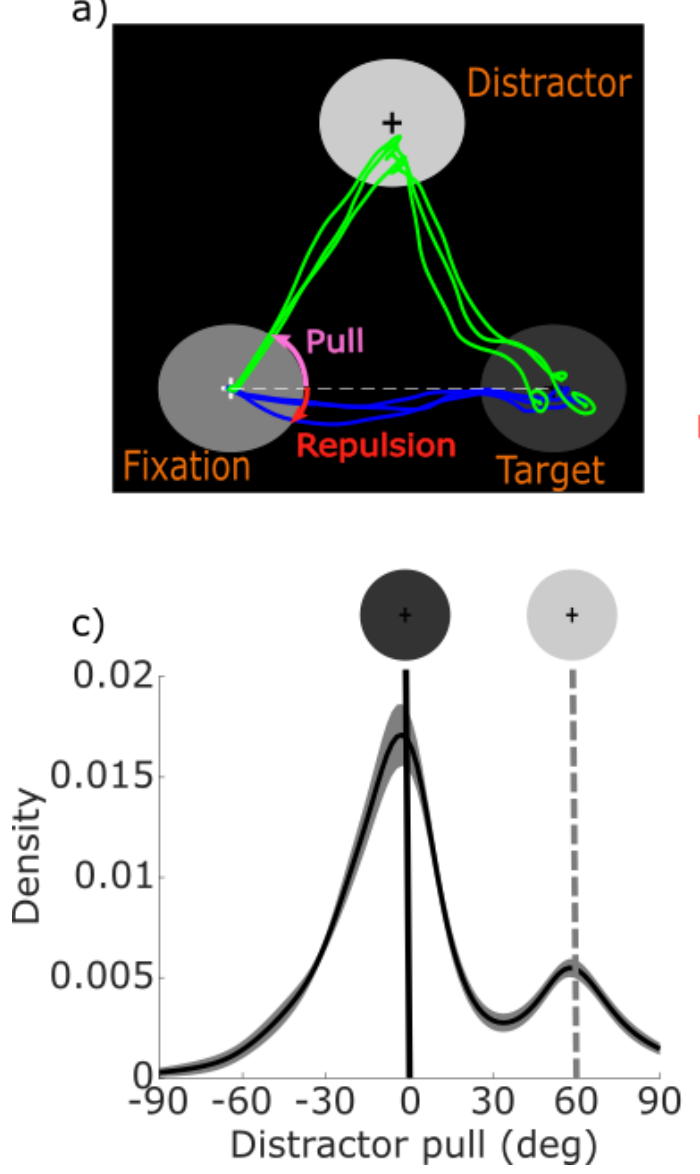

b)

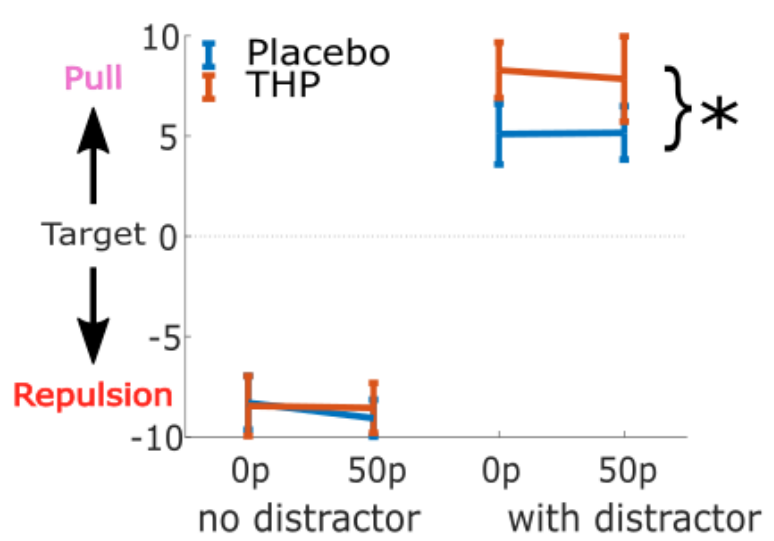

d)

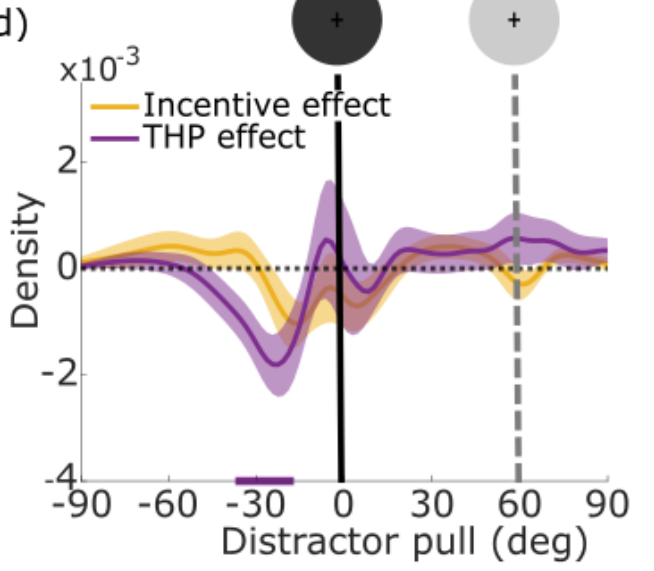

Figure 2. Muscarinic blockade increases the pull from salient distractors. a) Sample saccades showing fixation at the bottom left circle, the target on the right, and the distractor on the top. Distractor pull is the angle of the eye when it leaves the fixation circle, relative to a straight line from the fixation to target circle (positive values reflect angles towards the distractor, zero is flat, negative reflects repulsion). b) Mean distractor pulls for low and high incentives when the salient distractor is and is not present. Distractor pull was negative (i.e. below the horizontal line in panel a) reflecting repulsion from the distractor when it did not light up. However, when the distractor did light up, distractor pull was positive, reflecting a bias towards it, and this bias was greater on THP than placebo. c) Mean kernel-smoothed density of distractor pulls for all trials with a distractor (averaged across all other conditions) with shading showing the within-subject standard errors. There is a smaller peak centred on the distractor's orientation (grey dashed line and circle). Negative distractor pulls show the repulsive bias away from the distractor location. d) Mean kernel-smoothed densities showing the effects of incentive (i.e. 50p - Op) and THP (i.e. THP - incentive) for all 'with distractor' trials. Cluster-based permutation testing showed that THP reduced the number of trials biased around $-30^{\circ}$, indicating reduced repulsive bias when muscarinic receptors are antagonised.

\section{Preparatory activity is modulated by incentive and acetylcholine}

265 We examined EEG activity in the delay period between the preparation cue and the target (and distractor) onset, first using two time-windows of interest, then a cluster-based permutation approach. There was an early fronto-central positive ERP with a peak around $220 \mathrm{~ms}$, consistent with the P3a (Figure 3a), which was then followed by a growing negative potential centrally, consistent with the CNV. From the grand-average ERP over all conditions, we chose $200-280 \mathrm{~ms}$ at $\mathrm{Cz}$ for the early ERP, and $1200-1500 \mathrm{~ms}$ at $\mathrm{Cz}$ for the CNV. Note that both these periods began $>1.5$ seconds after the incentive was presented.

Prior to the preparation cue (900 to $1100 \mathrm{~ms}$ after incentive cue, baselining at the incentive cue; green shaded area in Figure 3a), THP strengthened negativity (Figure 3b, $\beta=-.0597, p<.0001$ ), but incentives had no effect or interaction $(p>.05)$. After the preparation cue, the early ERP (Figure $3 c$ ) 
bioRxiv preprint doi: https://doi org/10.1101/2021.07.28.454154; this version posted July 29,2021 . The copyright holder for this preprin (which was not certified by peer review) is the author/funder, who has granted bioRxiv a license to display the preprint in perpetuity. It is made available under aCC-BY 4.0 International license.

275 was significantly smaller for high incentive trials $(\beta=-0.01868, p=.0142$; see Table S2 for full ERP statistics). The subsequent CNV was strengthened (i.e. more negative; Figure $\mathbf{3 d}$ ) by incentive ( $\beta=$ $.0928, p<.0001)$ and THP $(\beta=-0.0502, p<.0001)$, with an interaction whereby THP decreased the incentive effect $(\beta=0.0172, p=.0213)$.

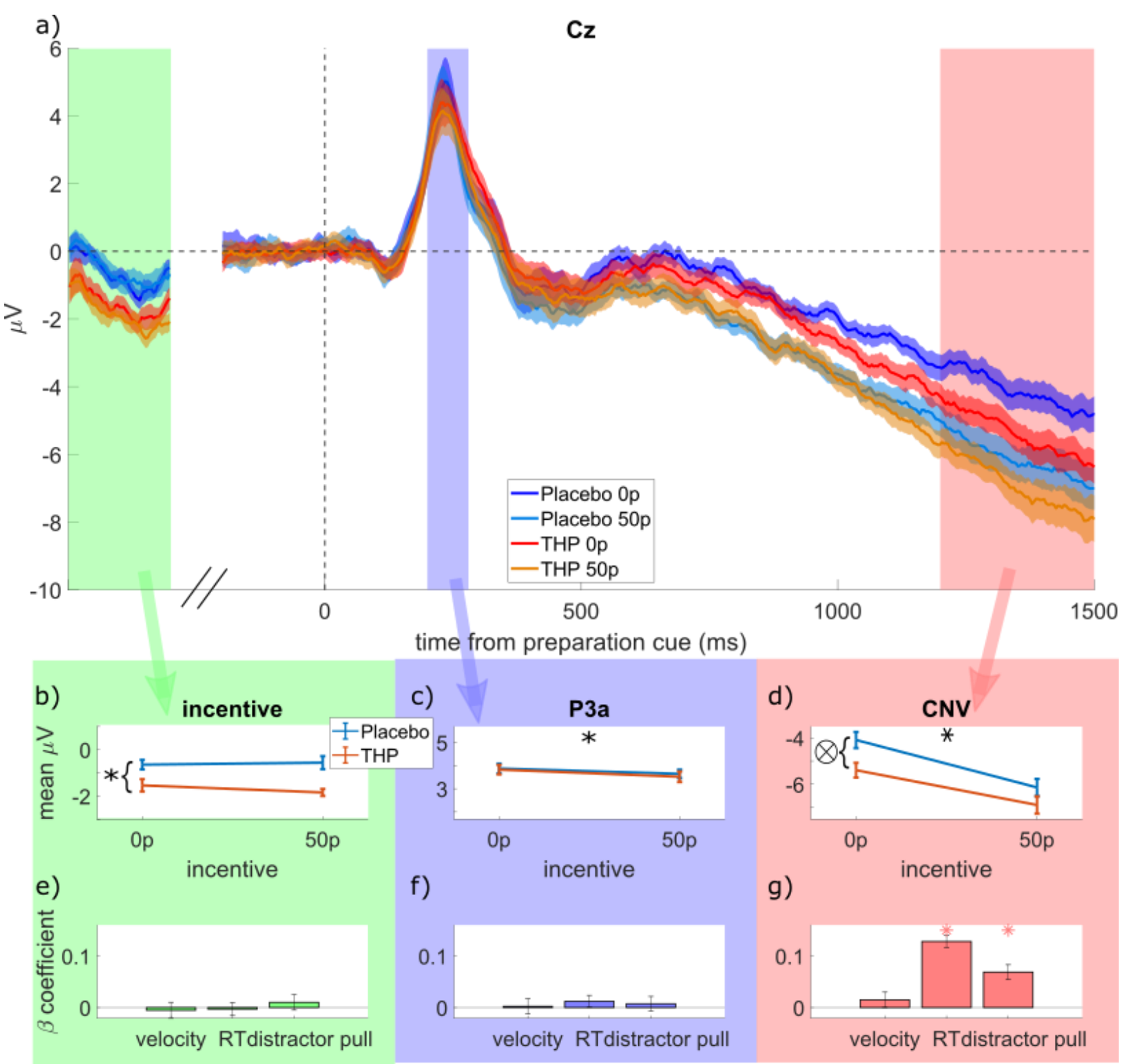

280 Figure 3. Mean ERP to the ready cue. a) Grand-average ERPs in electrode Cz split for the four conditions (low \& high incentive, placebo \& THP). The three time-windows are highlighted in different colours, and correspond to the columns of panels below. The 'incentive' window is a non-contiguous window of 900-1100ms after the incentive cue, which contains the late negative potential after the incentive cue. $b$-d) The mean voltages within each time-window for the different incentive and drug conditions. b) Late ERP to the incentive cue (900:1100ms at Cz) was more negative when on THP than placebo, but it was not affected by incentive ( $p>.05)$. c) Mean P3a (200:280ms after the preparation cue) is decreased by high incentives but unaffected by THP. d) The CNV (1200:1500ms after the preparation cue) is strengthened (more negative) by incentives and THP, with a weak interaction $(p=.0213)$ as THP slightly reduces the incentive effect (flatter slope for the orange line; and THP lines are closer than Placebo lines in panel a). e-g) The $\beta$ coefficients from regressing each component against each behavioural variable, with stars representing significant ( $p<.0056$; Bonferroni-corrected for 9 comparisons) associations (error bars are $95 \% \mathrm{Cl}$ ).

This suggests that while incentives and muscarinic antagonism both strengthen the CNV, these effects are not additive, and actually attenuate when both are present. The early ERP also showed 
incentive effects, but no drug effects. The CNV results are thus similar to those of residual velocity, but before testing that, we assessed whether other regions and times may be affected by incentives and THP.

\section{Permutation testing:}

Cluster-based permutation testing on difference waves ( 2500 iterations, family-wise error rate $=.05$; DMGroppe Mass Univariate toolbox; Groppe, Urbach, \& Kutas, 2011) yielded effects of incentive, THP and the interaction of the two across all electrodes and time-points. We found a significant

300 cluster for an incentive effect, across centro-parietal electrodes from around $400 \mathrm{~ms}$ onwards, which strengthened over time (Figure 4a). There were no significant clusters of difference for the THP effect or the THP*Incentive interaction.

As this cluster-based approach did not pick up the CNV drug effect, we also averaged each electrode within the 1200:1500ms window, and ran the three-way regression on each electrode separately.

305 This found an incentive*THP interaction for $\mathrm{Cz}, \mathrm{CPz}$ and $\mathrm{Pz}$ electrodes, which did not survive Bonferroni-correction.

\section{Neural preparation predicts RT and distraction}

We regressed the mean amplitude of the pre-preparation activity, P3a and CNV against velocity, RT and distractor pull (including incentive, distractor and drug conditions as covariates), and Bonferroni-

310 corrected the $p$-values for 9 multiple comparisons. Pre-preparation and P3a did not predict any behavioural variable (Figure 3e-f), while CNV predicted RT and distractor pull (Figure 3g, $p<.0001$; see Table S3).

As time-window and cluster-based analyses above differed slightly, with only the former showing the THP*incentive interaction seen for velocity and RT, we also used a window-free approach to the

315 regressions. To more closely compare neural and behavioural effects, we regressed each electrode and time-point against the three behavioural variables, while controlling for effects of incentive, distractor, THP, the interactions of those factors, and a random effect of participant. This analysis therefore asks whether trial-to-trial neural variability predicts behavioural variability. We Bonferroni corrected the $p$-values (61 channels * 410 time-points: $\alpha=.000001992)$. Velocity, RT and distraction

320 were predicted by preparatory EEG voltages before the onset of the target, each with distinct patterns (Figure 5). Residual velocity was significantly predicted by right frontal electrodes from about 1000 ms onwards, which was strongest on electrode AF8. This did not encompass electrode $\mathrm{Cz}$. RT was strongly predicted by EEG voltage over a very large scalp area, centred on Cz from about $700 \mathrm{~ms}$ onwards. Distractor pull was also predicted by many electrodes, although strongest in the 325 frontal-midline from about $400 \mathrm{~ms}$.

To check that these associations were not confounded by correlations between the saccadic measures themselves (note that RT is negatively correlated with residual velocity; $r=-.0681, p<$ .0001 ), we re-ran this analysis while controlling for the other two saccadic measures. This did not materially change the results, indicating that preparatory EEG predicts these aspects of performance independently. 
bioRxiv preprint doi: https://doi.org/10.1101/2021.07 28.454154 this version posted July 29, 2021. The copyright holder for this preprin (which was not certified by peer review) is the author/funder, who has granted bioRxiv a license to display the preprint in perpetuity. It is made available under aCC-BY 4.0 International license.
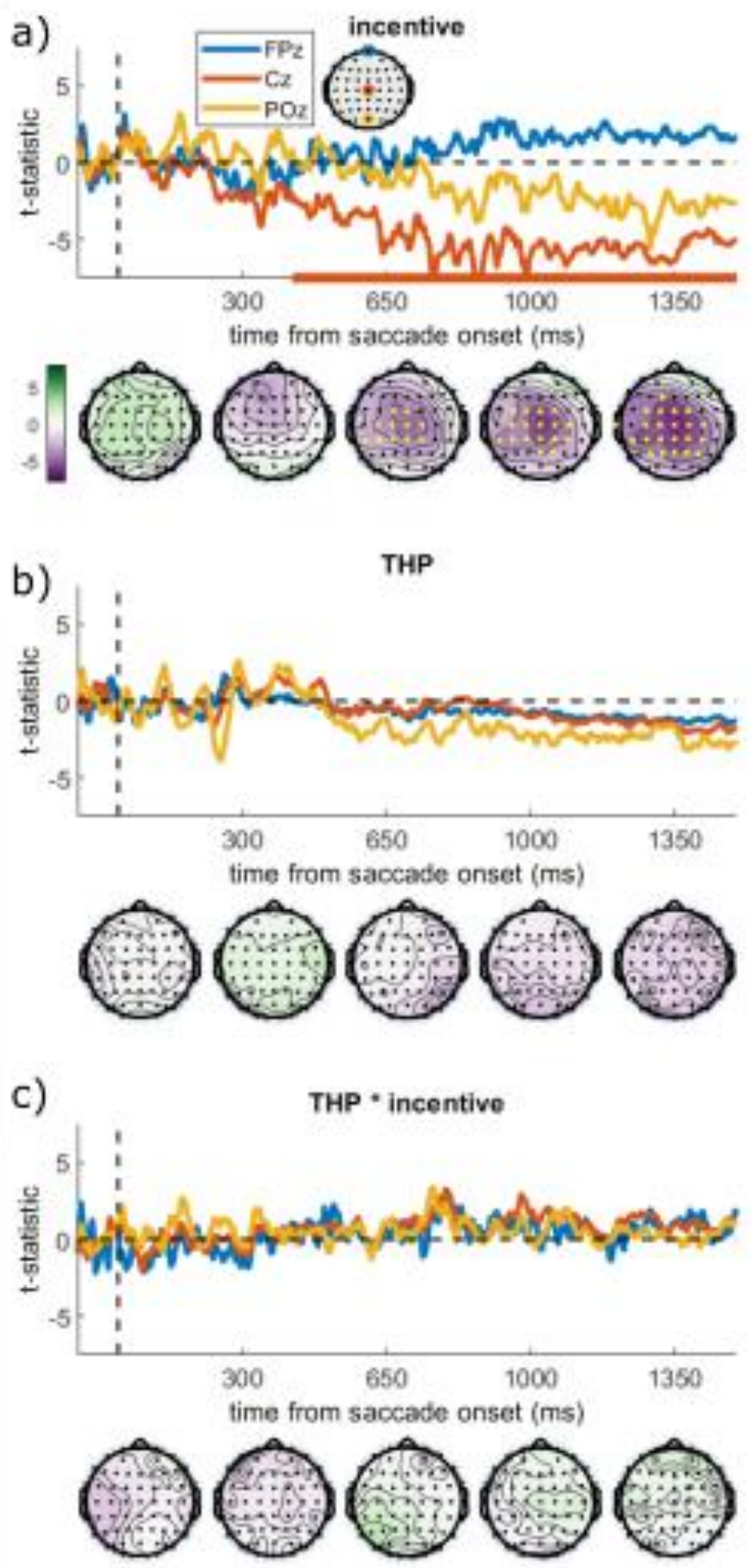

Figure 4. Cluster-based permutation testing of difference waves for different effects, with topoplots below. a) T-statistics for the incentive difference wave (i.e. 50p - Op, averaged across other factors) for three selected channels, with the solid bar at 335 the bottom showing significant clusters (FWER =.05). The topoplots below show the $t$-statistics for all channels at the times written on the $x$-axis, with the yellow dots representing electrodes in significant clusters. Higher incentives lead to more negative voltages centro-posteriorly from about 400ms after the preparation cue began, and this increases over the epoch. B) t-statistics for the drug difference wave (THP - placebo) shows no significant clusters at any channels or time-points, suggesting that THP did not change the voltage overall. C) Difference of difference waves showing the THP*incentive interaction ( (drug 50p-0p) - (placebo 50p-0p)), also shows no cluster of significant difference. 


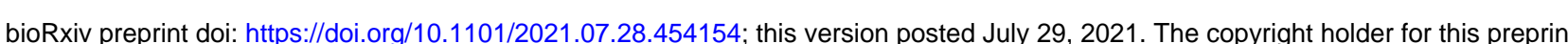
(which was not certified by peer review) is the author/funder, who has granted bioRxiv a license to display the preprint in perpetuity. It is made available under aCC-BY 4.0 International license.

a)
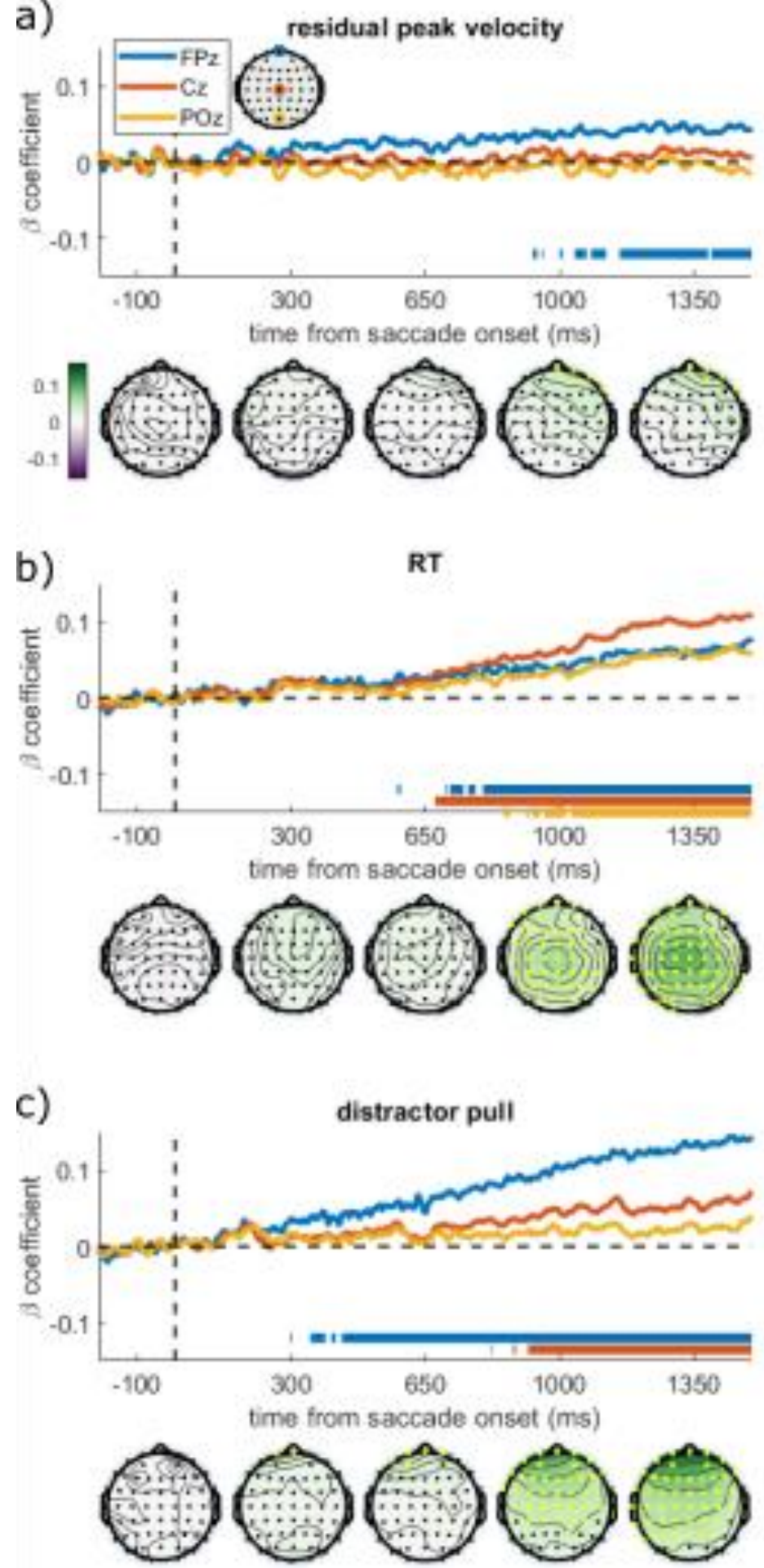

Figure 5. Regression coefficients from regressing each electrode and time-point against the different behavioural variables. The time series show the regression coefficients for three chosen electrodes, with the solid bars at the bottom showing significant time-points for those electrodes (Bonferroni-corrected). Topoplots are shown below the graph at the times written on the $x$-axis, with the colours showing the regression coefficient and yellow electrodes showing significant associations. a) Residual velocity is predicted by voltage in the frontal central and right electrodes from about 1000ms onwards. b) RT is predicted by central electrodes from about 700ms onwards, spreading to almost all electrodes by $1000 \mathrm{~ms}$. c) Distractor pull is predicted by frontal electrodes from about $400 \mathrm{~ms}$, spreading posteriorly over time to reach most electrodes by $1500 \mathrm{~ms}$. 
We have found that neural preparatory activity can predict residual velocity and RT, and is also affected by incentives and THP. Finally we ask whether the neural activity can explain the effects of incentives and THP, through mediation analyses (Muller, Judd, \& Yzerbyt, 2005).

As distractor pull was not affected by incentive, we only examined residual velocity and RT, and used

linear mixed effects modelling to test the mediation. We used the electrodes with the strongest associations for each measure (AF8 for residual velocity and Cz for RT), and averaged them over 1200 to $1500 \mathrm{~ms}$. As Figure 6 shows, Cz partially mediated the incentive effect on RT but not residual velocity. AF8 activity did not mediate either residual velocity or RT. This suggests preparatory negativity is a marker for invigoration of RT by incentives, but not movement energisation.

360 We also investigated whether either electrode could explain the cholinergic reduction in motivation (THP*incentive interaction) on RT - i.e. whether CNV mediated the THP moderation (Figure 6c). CNV mediated this moderation for RT, with both the influence of incentive on CNV, and CNV on RT being moderated by THP. This indicates cholinergic blockade changes how incentives affect preparatory negativity, and how this negativity reflects RT, which can explain some of the reduced invigoration of RT. However, this was not observed for saccade velocity.

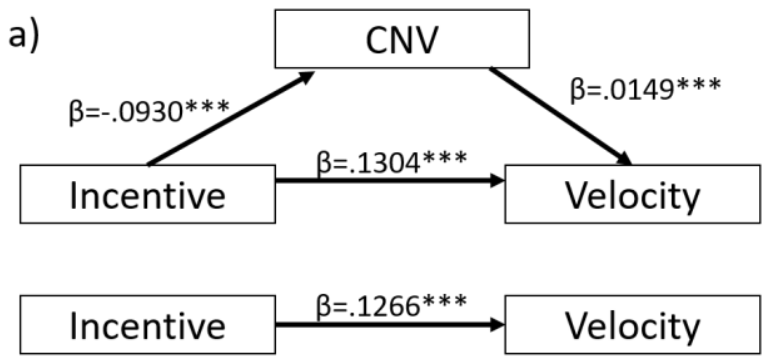

b)

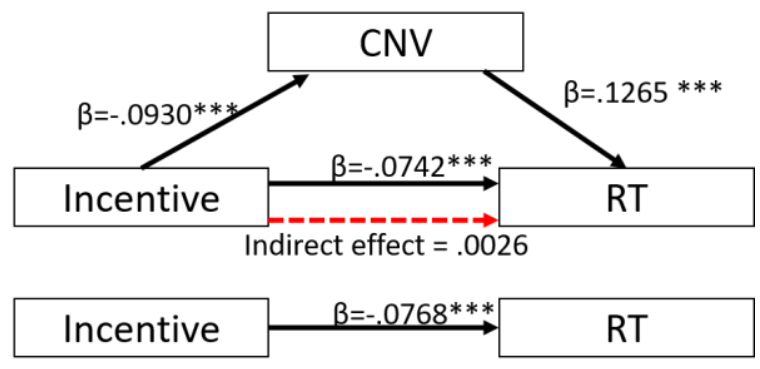

c)

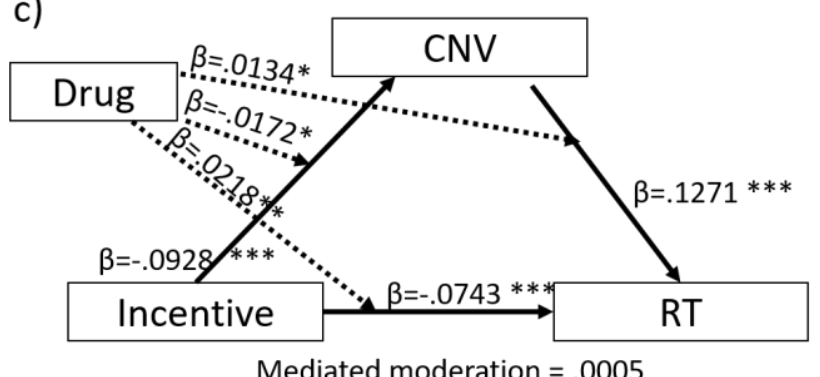

Figure 6. Mediation analyses of late ERP activity on residual velocity and RT. Top row shows the mediations of the mean CNV amplitude (1200 to $1500 \mathrm{~ms}$ ) in electrode Cz, and the bottom row shows mediated moderation. The left side shows residual velocity and the right side $R T$. Black lines are significant associations, dashed red lines are indirect effects showing

370 the size of the partial mediation, and dotted black lines are moderations. Cz mean amplitude mediated the effect of incentive on RT but not residual velocity, and also mediated the moderation of incentive by THP.

\section{Discussion}

When incentivised, participants initiated movements faster, and with faster velocity, but these motivational effects were reduced by blocking muscarinic acetylcholine receptors with THP (Figure

375 1d-e). THP also reduced repulsion away from a salient distractor (Figure 2b). The CNV, a frontocentral signal believed to reflect premotor preparatory activation, was stronger when incentives were present, and with THP (Figure 3d), and crucially, THP reduced the incentive benefit on CNV, 
mirroring the behavioural effects. Neural preparation predicted RT and distractibility (Figure $\mathbf{3 g}$ ), with distinct scalp distributions (Figure 5a-c). The CNV partially mediated the incentivisation of RT (Figure 6b), and could explain the drug-induced reduction in incentivisation of RT via a mediated moderation (Figure $6 \mathbf{c}$ ). No such associations were seen in the window before the preparation cue onset, suggesting these effects relate specifically to preparing motivated action, rather than simply an incentive effect (Figure $\mathbf{3 b} \boldsymbol{\&} \mathbf{e}$ ).

These results demonstrate a role of acetylcholine, and specifically muscarinic M1 receptors, in motivation in humans. As antagonising M1rs reduced the incentivisation of residual peak velocity and saccadic RT, we can assume that M1rs normally play a facilitating role. This mirrors some studies using antimuscarinics in animals to impair motivation (Collins et al., 2016; Ostlund et al., 2014; Pratt \& Kelley, 2004), although those studies used scopolamine which antagonises M1-like and M2-like receptors, so effects may have been due to $\mathrm{M} 2 \mathrm{r}$ antagonism. This complements previous work demonstrating that nicotine increases reward responsiveness (Wang et al., 2020).

The CNV in the lead up to the target appearing was strengthened by the incentives, replicating previous work (Frömer et al., 2021; B. K. Novak et al., 2016; K. D. Novak \& Foti, 2015; Schevernels, Krebs, Santens, Woldorff, \& Boehler, 2014). M1r antagonism reduced the effect of incentives on CNV, mirroring the reduced incentivisation on RT and residual velocity. CNV amplitude predicted RT, 395 along with distractor pull, and frontal activity in this same time-window predicted residual velocity. This aligns with recent studies linking CNV to RT and accuracy (Frömer et al., 2021), and to incentivisation of effort (Berchio et al., 2019). Our associations held up even when controlling for the other behavioural variables, suggesting they were not due to factors such as the negative correlation of RT and velocity.

400 The CNV has been linked to activity in the thalamus, supplementary motor area, cingulate and ventral striatum (Nagai et al., 2004; Plichta et al., 2013), and to a range of neurotransmitters including dopamine (Linssen et al., 2011) which also modulates motivational effects on vigour (Grogan et al., 2020; Manohar \& Husain, 2015). M1r activation in the striatum can modulate the excitability of indirect and direct pathways (Galarraga et al., 1999; Shen, Hamilton, Nathanson, \&

405 Surmeier, 2005), and increase dopamine release (de Klippel, Sarre, Ebinger, \& Michotte, 1993), which are potential mechanisms for muscarinic motivation in humans.

The mediation analysis showed the incentivisation of RT could be partially explained by stronger CNV amplitudes, as could the antimuscarinic reduction in incentivisation. This mediated moderation was due to both reduced incentivisation of the CNV and reduced influence of the CNV on RT. These

410 effects were rather small, which suggests the presence of an additional direct way for drug to affect incentivisation, perhaps via subcortical routes (Faure, Tolu, Valverde, \& Naudé, 2014; Mark et al., 2011; Mena-Segovia, Winn, \& Bolam, 2008). There were no such mediations to explain the incentivisation of residual velocity, suggesting the CNV is not associated with the motivational preparation of motor speed. Animal studies link saccadic velocity to the instantaneous firing rate in the superior colliculus (Smalianchuk, Jagadisan, \& Gandhi, 2018), which is inaccessible to EEG recordings, although as the motivational modulation of this activity presumably arises from cortex. Future investigations of other aspects of the EEG signals may illuminate us.

One potentially confusing finding is that although stronger CNV benefits RT (Frömer et al., 2021; Novak \& Foti, 2015) M1r antagonism strengthened the CNV while slowing RT. The mediated moderation we found indicates that THP changes how CNV predicts RT, which suggests that THP has 
two effects: one upstream of the CNV strengthening anticipation, and one downstream, decreasing the coupling to RT. The former could be the ventral striatal activity found to drive the CNV (Plichta et al., 2013), while the latter could reflect drug-induced changes in non-motivational cholinergic systems (Gritton et al., 2016).

425 While we have interpreted these effects as due to incentivisation, other closely related factors cannot be ruled out. When incentivised on this task, people expend more effort and also have a higher expectation of reward, which is linked to the effort they expend. Therefore it is possible that the $\mathrm{CNV}$ is measuring the greater expected reward induced by motivation, which is linked to faster saccades (Haith, Reppert, \& Shadmehr, 2012; Shadmehr, Reppert, Summerside, Yoon, \& Ahmed,

430 2019). The fact that no associations were seen between behaviour and neural activity in the timewindow before the preparation cue might suggest that factors such as expected reward or arousal are less likely to explain our results. However, these explanations cannot be fully disentangled in this paradigm.

We found that M1r antagonism led to a greater bias of distractor pull angles towards a salient

435 distractor, which was unaffected by incentives. This fits with previous studies finding cholinergic involvement in attention and distraction (Gritton et al., 2016; Laube et al., 2017; Sarter et al., 2016). However, we did not observe clear motivational improvements in distractibility, which have been seen previously (Hickey \& Van Zoest, 2012). This may be less surprising considering that the speedaccuracy trade-off dictates worse accuracy for faster saccades (Reppert, Servant, Heitz, \& Schall,

440 2018) which is sensitive to the rewards available for responses (Hickey \& Van Zoest, 2012). Any motivational distraction effects might be weak in this study because the incentive schedule strongly favoured faster responses, and distractors were only present on half the trials, reducing the value of greater cognitive control. The repulsive bias away from the distractor was weakened by THP (Figure 2d), which may be a behavioural manifestation of reduced reactive top-down control reported with

445 muscarinic antagonism (Laube et al., 2017). But in our data, the distractor pull could be predicted by preparatory activity over 1 second before the target onset, and this was also affected by muscarinic blockade. The frontal signature of distractor pull was distinct to the pattern predicting RT, suggesting that cholinergic effects on proactive control and speed are dissociable.

The effects of acetylcholine on motivation are of crucial importance in Parkinson's disease, where

450 the balance between dopamine and acetylcholine is disrupted (Pisani, Bernardi, Ding, \& Surmeier, 2007; Schulz, Pagano, Fernández Bonfante, Wilson, \& Politis, 2018), leading to apathy or impulsivity (Devos et al., 2014). As trihexyphenidyl is often used to treat symptoms of Parkinson's disease, the finding that it impairs motivation suggests that it may worsen motivational symptoms in a population already troubled by apathy.

\section{Conclusion}

Muscarinic M1r antagonism reduced the incentivisation of saccadic peak velocity and RT, suggesting that normally M1r activity is important for motivation. The incentives strengthened the CNV, a preparatory EEG component, and this mediated the incentivisation of RT and the reduction of this incentivisation by the drug, implicating the CNV as a potential marker of muscarinic invigoration.

\section{Acknowledgements}

The authors would like to thank Andrea Bocincova and Yongzhi Huang for help with EEG set up and analysis. The work was funded by a Medical Research Council Clinician Scientist Fellowship to SGM 
(MR/P00878X). MVS was funded by the Medical Research Council (MC_ST_U16042). MJG is funded by the Jon Mouton Charity Trust (Guernsey). The Refa72 was funded by the Academy of Medical Sciences, Starter Grant for Clinical lecturers (MJG). The scheme is generously supported by the Wellcome Trust, Medical Research Council, British Heart Foundation, Versus Arthritis, Diabetes UK and British Thoracic Society (through the Helen and Andrew Douglas bequest).

\section{Author Contributions}

Conceptualization: SGM, JPG. Data curation: JPG. Formal Analysis: JPG. Funding acquisition: SGM.

470 Investigation: JPG, MR, MvS. Methodology: JPG, SGM. Project administration: JPG. Resources: MJG, ALG. Supervision: SGM. Validation: JPG. Visualisation: JPG. Writing - original draft: JPG. Writing review \& editing: JPG, SGM, MR, MvS, ALG, MJG.

\section{Competing interests}

The authors declare that no competing interests exist.

\section{References}

Ansseau, M., Machowski, R., Franck, G., \& Timsit-Berthier, M. (1985). REM sleep latency and contingent negative variation in endogenous depression suggestion for a common cholinergic mechanism. Biological Psychiatry, 20(12), 1303-1307. https://doi.org/10.1016/00063223(85)90115-5

Bahill, A. T., Clark, M. R., \& Stark, L. (1975). The main sequence, a tool for studying human eye movements. Mathematical Biosciences, 24(3-4), 191-204. https://doi.org/10.1016/00255564(75)90075-9

Beierholm, U., Guitart-Masip, M., Economides, M., Chowdhury, R., Düzel, E., Dolan, R., \& Dayan, P. (2013). Dopamine modulates reward-related vigor. Neuropsychopharmacology, 38(8), 14951503. https://doi.org/10.1038/npp.2013.48

Berchio, C., Rodrigues, J., Strasser, A., Michel, C. M., \& Sandi, C. (2019). Trait anxiety on effort allocation to monetary incentives: a behavioral and high-density EEG study. Translational Psychiatry, 9(1). https://doi.org/10.1038/s41398-019-0508-4

Blundell, J., Frisson, S., Chakrapani, A., Gissen, P., Hendriksz, C., Vijay, S., \& Olson, A. (2018). Oculomotor abnormalities in children with Niemann-Pick type C. Molecular Genetics and Metabolism, 123(2), 159-168. https://doi.org/10.1016/j.ymgme.2017.11.004

Brunia, C. H. M., van Boxtel, G. J. M., \& Böcker, K. B. E. (2012). Negative Slow Waves as Indices of Anticipation: The Bereitschaftspotential, the Contingent Negative Variation, and the StimulusPreceding Negativity. In The Oxford Handbook of Event-Related Potential Components (pp. 132). https://doi.org/10.1093/oxfordhb/9780195374148.013.0108

Cachope, R., \& Cheer, J. F. (2014). Local control of striatal dopamine release. Frontiers in Behavioral Neuroscience, 8(MAY), 1-7. https://doi.org/10.3389/fnbeh.2014.00188

Collins, A. L., Aitken, T. J., Greenfield, V. Y., Ostlund, S. B., \& Wassum, K. M. (2016). Nucleus accumbens acetylcholine receptors modulate dopamine and motivation. Neuropsychopharmacology, 41(12), 2830-2838. https://doi.org/10.1038/npp.2016.81

Collins, A. L., Aitken, T. J., Huang, I. W., Shieh, C., Greenfield, V. Y., Monbouquette, H. G., ... Wassum, 
K. M. (2019). Nucleus Accumbens Cholinergic Interneurons Oppose Cue-Motivated Behavior. Biological Psychiatry, 86(5), 388-396. https://doi.org/10.1016/j.biopsych.2019.02.014

Da Silva, J. A., Tecuapetla, F., Paixão, V., \& Costa, R. M. (2018). Dopamine neuron activity before action initiation gates and invigorates future movements. Nature, 554(7691), 244-248. https://doi.org/10.1038/nature25457

de Klippel, N., Sarre, S., Ebinger, G., \& Michotte, Y. (1993). Effect of M1- and M2-muscarinic drugs on striatal dopamine release and metabolism: an in vivo microdialysis study comparing normal and 6-hydroxydopamine-lesioned rats. Brain Research, 630(1-2), 57-64. https://doi.org/10.1016/0006-8993(93)90642-Z

Delorme, A., \& Makeig, S. (2004). EEGLAB: an open source toolbox for analysis of single-trial EEG dynamics including independent component analysis. Journal of Neuroscience Methods, 134, 9-21.

Devos, D., Moreau, C., Maltête, D., Lefaucheur, R., Kreisler, A., Eusebio, A., ... Dujardin, K. (2014). Rivastigmine in apathetic but dementia and depression-free patients with Parkinson's disease: A double-blind, placebo-controlled, randomised clinical trial. Journal of Neurology, Neurosurgery and Psychiatry, 85(6), 668-674. https://doi.org/10.1136/jnnp-2013-306439

Dimigen, O., Sommer, W., Hohlfeld, A., Jacobs, A. M., \& Kliegl, R. (2011). Coregistration of eye movements and EEG in natural reading: Analyses and review. Journal of Experimental Psychology: General, 140(4), 552-572. https://doi.org/10.1037/a0023885

Dudman, J. T., \& Krakauer, J. W. (2016). The basal ganglia: From motor commands to the control of vigor. Current Opinion in Neurobiology, 37, 158-166. https://doi.org/10.1016/j.conb.2016.02.005

Ebenezer, I. S. (1986). The effects of atropine on event-related slow potentials in the rat. European Journal of Pharmacology, 120(3), 371-374. https://doi.org/10.1016/0014-2999(86)90481-4

Fahed, M., \& Steffens, D. C. (2021). Apathy : Neurobiology , Assessment and Treatment. Clinical Psychopharmacology and Neuroscience, 19(2), 181-189.

Faure, P., Tolu, S., Valverde, S., \& Naudé, J. (2014). Role of nicotinic acetylcholine receptors in regulating dopamine neuron activity. Neuroscience, 282, 86-100. https://doi.org/10.1016/j.neuroscience.2014.05.040

Forster, G. L., \& Blaha, C. D. (2000). Laterodorsal tegmental stimulation elicits dopamine efflux in the rat nucleus accumbens by activation of acetylcholine and glutamate receptors in the ventral tegmental area. European Journal of Neuroscience, 12(10), 3596-3604. https://doi.org/10.1046/j.1460-9568.2000.00250.x

535 Frömer, R., Lin, H., Dean Wolf, C. K., Inzlicht, M., \& Shenhav, A. (2021). Expectations of reward and efficacy guide cognitive control allocation. Nature Communications, 12(1), 1030. https://doi.org/10.1038/s41467-021-21315-z

Galarraga, E., Herna, S., Reyes, A., Miranda, I., Bermudez-rattoni, F., \& Vilchis, C. (1999). Cholinergic Modulation of Neostriatal Output : A Functional Antagonism between Different Types of Muscarinic Receptors. The Journal of Neuroscience, 19(9), 3629-3638.

Gritton, H. J., Howe, W. M., Mallory, C. S., Hetrick, V. L., Berke, J. D., \& Sarter, M. (2016). Cortical cholinergic signaling controls the detection of cues. Proceedings of the National Academy of Sciences of the United States of America, 113(8), E1089-E1097. 
https://doi.org/10.1073/pnas.1516134113

545

Grogan, J. P., Sandhu, T. R., Hu, M. T., \& Manohar, S. G. (2020). Dopamine promotes instrumental motivation, but reduces reward-related vigour. ELife, 9, 1-20.

https://doi.org/10.7554/elife.58321

Groppe, D. M., Urbach, T. P., \& Kutas, M. (2011). Mass univariate analysis of event-related brain potentials/fields I: A critical tutorial review. Psychophysiology, 48(12), 1711-1725. https://doi.org/10.1111/j.1469-8986.2011.01273.x

Hailwood, J. M., Heath, C. J., Philips, B. U., Robbins, T. W., Saksida, L. M., \& Bussey, T. J. (2019). Blockade of muscarinic acetylcholine receptors facilitates motivated behaviour and rescues a model of antipsychotic- induced amotivation. Neuropsychopharmacology, 44, 1068-1075. https://doi.org/10.1038/s41386-018-0281-8

Haith, A. M., Reppert, T. R., \& Shadmehr, R. (2012). Evidence for hyperbolic temporal discounting of reward in control of movements. Journal of Neuroscience, 32(34), 11727-11736. https://doi.org/10.1523/JNEUROSCI.0424-12.2012

Hickey, C., \& Van Zoest, W. (2012). Reward creates oculomotor salience. Current Biology, 22(7), R219-R220. https://doi.org/10.1016/j.cub.2012.02.007

Hoebel, B. G., Avena, N. M., \& Rada, P. (2007). Accumbens dopamine-acetylcholine balance in approach and avoidance. Current Opinion in Pharmacology, 7(6), 617-627. https://doi.org/10.1016/j.coph.2007.10.014

Ikeda, A., Shibasaki, H., Kaji, R., Terada, K., Nagamine, T., Honda, M., \& Kimura, J. (1997). Dissociation between contingent negative variation (CNV) and Bereitschaftspotential (BP) in patients with parkinsonism. Electroencephalography and Clinical Neurophysiology, 102(2), 142-151. Retrieved from http://www.ncbi.nlm.nih.gov/pubmed/9060866

Kleiner, M., Brainard, D., Pelli, D., Ingling, A., Murray, R., Broussard, C., \& Cornelissen, F. (2007). What's new in Psychtoolbox-3? A free cross-platform toolkit for Psychophysics with Matlab \&amp; GNU/Octave. Perception, 36(14), 1.

Laube, I., Matthews, N., Dean, A. J., O'Connell, R. G., Mattingley, J. B., \& Bellgrove, M. A. (2017). Scopolamine reduces electrophysiological indices of distractor suppression: Evidence from a contingent capture task. Frontiers in Neural Circuits, 11(December), 1-14. https://doi.org/10.3389/fncir.2017.00099

Linssen, A. M. W., Vuurman, E. F. P. M., Sambeth, A., Nave, S., Spooren, W., Vargas, G., ... Riedel, W. J. (2011). Contingent negative variation as a dopaminergic biomarker: Evidence from doserelated effects of methylphenidate. Psychopharmacology, 218(3), 533-542. https://doi.org/10.1007/s00213-011-2345-x

Lopez-Calderon, J., \& Luck, S. J. (2014). ERPLAB: An open-source toolbox for the analysis of eventrelated potentials. Frontiers in Human Neuroscience, 8(1 APR), 1-14. https://doi.org/10.3389/fnhum.2014.00213

Manohar, S. G., Finzi, R. D., Drew, D., \& Husain, M. (2017). Distinct Motivational Effects of Contingent and Noncontingent Rewards. Psychological Science, 095679761769332. https://doi.org/10.1177/0956797617693326

Manohar, S. G., \& Husain, M. (2015). Reduced pupillary reward sensitivity in Parkinson's disease. Npj 
Manohar, S. G., Muhammed, K., Fallon, S. J., \& Husain, M. (2019). Motivation dynamically increases noise resistance by internal feedback during movement. Neuropsychologia, 123, 19-29. https://doi.org/10.1016/j.neuropsychologia.2018.07.011

Mark, G. P., Shabani, S., Dobbs, L. K., \& Hansen, S. T. (2011). Cholinergic modulation of mesolimbic dopamine function and reward. Physiology and Behavior, 104(1), 76-81. https://doi.org/10.1016/j.physbeh.2011.04.052

Mazzoni, P., Hristova, A., \& Krakauer, J. W. (2007). Why Don't We Move Faster? Parkinson's Disease, Movement Vigor, and Implicit Motivation. The Journal of Neuroscience, 27(27), 7105-7116. https://doi.org/10.1523/JNEUROSCI.0264-07.2007

McGuigan, S., Zhou, S., Brosnan, M. B., Thyagarajan, D., Bellgrove, M. A., \& Chong, T. T.-J. (2019). Dopamine restores cognitive motivation in Parkinson's disease. Brain, $(x), 1-11$. https://doi.org/10.1093/brain/awy341

Mena-Segovia, J., Winn, P., \& Bolam, J. P. (2008). Cholinergic modulation of midbrain dopaminergic systems. Brain Research Reviews, 58(2), 265-271.

600 https://doi.org/10.1016/j.brainresrev.2008.02.003

Muhammed, K., Dalmaijer, E., Manohar, S. G., \& Husain, M. (2018). Voluntary modulation of saccadic peak velocity associated with individual differences in motivation. Cortex. https://doi.org/10.1016/J.CORTEX.2018.12.001

Muller, D., Judd, C. M., \& Yzerbyt, V. Y. (2005). When moderation is mediated and mediation is moderated. Journal of Personality and Social Psychology, 89(6), 852-863. https://doi.org/10.1037/0022-3514.89.6.852

Nagai, Y., Critchley, H. D., Featherstone, E., Fenwick, P. B. C., Trimble, M. R., \& Dolan, R. J. (2004). Brain activity relating to the contingent negative variation: An $\mathrm{fMRI}$ investigation. Neurolmage, 21(4), 1232-1241. https://doi.org/10.1016/j.neuroimage.2003.10.036

Novak, B. K., Novak, K. D., Lynam, D. R., \& Foti, D. (2016). Individual differences in the time course of reward processing: Stage-specific links with depression and impulsivity. Biological Psychology, 119, 79-90. https://doi.org/10.1016/j.biopsycho.2016.07.008

Novak, K. D., \& Foti, D. (2015). Teasing apart the anticipatory and consummatory processing of monetary incentives: An event-related potential study of reward dynamics. Psychophysiology, 52(11), 1470-1482. https://doi.org/10.1111/psyp.12504

Nunes, E. J., Randall, P. A., Podurgiel, S., Correa, M., \& Salamone, J. D. (2013). Nucleus accumbens neurotransmission and effort-related choice behavior in food motivation: Effects of drugs acting on dopamine, adenosine, and muscarinic acetylcholine receptors. Neuroscience and Biobehavioral Reviews, 37(9), 2015-2025. https://doi.org/10.1016/j.neubiorev.2013.04.002

620 Ostlund, S. B., Kosheleff, A. R., \& Maidment, N. T. (2014). Differential effects of systemic cholinergic receptor blockade on Pavlovian incentive motivation and goal-directed action selection. Neuropsychopharmacology, 39(6), 1490-1497. https://doi.org/10.1038/npp.2013.348

Pagonabarraga, J., Kulisevsky, J., Strafella, A. P., \& Krack, P. (2015). Apathy in Parkinson's disease: Clinical features, neural substrates, diagnosis, and treatment. The Lancet Neurology, 14(5), 518-531. https://doi.org/10.1016/S1474-4422(15)00019-8

Papart, P., Ansseau, M., \& Timsit-Berthier, M. (1997). Influence of diazepam on contingent negative variation. Human Psychopharmacology, 12(2), 95-98. https://doi.org/10.1002/(SICI)1099- 
1077(199703/04)12:2<95::AID-HUP841>3.0.CO;2-3

Pirch, J. H., Corbus, M. J., Rigdon, G. C., \& Lyness, W. H. (1986). Generation of cortical event-related slow potentials in the rat involves nucleus basalis cholinergic innervation. Electroencephalography and Clinical Neurophysiology, 63, 464-475.

Pisani, A., Bernardi, G., Ding, J., \& Surmeier, D. J. (2007). Re-emergence of striatal cholinergic interneurons in movement disorders. Trends in Neurosciences, 30(10), 545-553. https://doi.org/10.1016/j.tins.2007.07.008

635 Plichta, M. M., Wolf, I., Hohmann, S., Baumeister, S., Boecker, R., Schwarz, A. J., ... Brandeis, D. (2013). Simultaneous EEG and fMRI reveals a causally connected subcortical-cortical network during reward anticipation. Journal of Neuroscience, 33(36), 14526-14533. https://doi.org/10.1523/JNEUROSCI.0631-13.2013

Pratt, W., \& Kelley, A. E. (2004). Nucleus Accumbens Acetylcholine Regulates Appetitive Learning and Motivation for Food via Activation of Muscarinic Receptors. Behavioural Neuroscience, 118(4), 730-739. Retrieved from http://psycnet.apa.org/buy/2004-16908-007

Renard, Y., Lotte, F., Gibert, G., Congedo, M., Maby, E., Delannoy, V., ... Lécuyer, A. (2010). OpenViBE: An open-source software platform to design, test, and use brain-computer interfaces in real and virtual environments. Presence: Teleoperators and Virtual Environments, 19(1), 35-53. https://doi.org/10.1162/pres.19.1.35

Reppert, T. R., Servant, M., Heitz, R. P., \& Schall, J. D. (2018). Neural mechanisms of speed-accuracy tradeoff of visual search: Saccade vigor, the origin of targeting errors, and comparison of the superior colliculus and frontal eye field. Journal of Neurophysiology, 120(1), 372-384. https://doi.org/10.1152/jn.00887.2017

Sarter, M., Lustig, C., Berry, A. S., Gritton, H., Howe, W. M., \& Parikh, V. (2016). What do phasic cholinergic signals do? Neurobiology of Learning and Memory, 130, 135-141. https://doi.org/10.1016/j.nlm.2016.02.008

Schevernels, H., Krebs, R. M., Santens, P., Woldorff, M. G., \& Boehler, C. N. (2014). Task preparation processes related to reward prediction precede those related to task-difficulty expectation. Neurolmage, 84, 639-647. https://doi.org/10.1016/j.neuroimage.2013.09.039

Schulz, J., Pagano, G., Fernández Bonfante, J. A., Wilson, H., \& Politis, M. (2018). Nucleus basalis of Meynert degeneration precedes and predicts cognitive impairment in Parkinson's disease. Brain, 1-16. https://doi.org/10.1093/brain/awy072

Shadmehr, R., De Xivry, J. J. O., Xu-Wilson, M., \& Shih, T. Y. (2010). Temporal discounting of reward and the cost of time in motor control. Journal of Neuroscience, 30(31), 10507-10516. https://doi.org/10.1523/JNEUROSCI.1343-10.2010

Shadmehr, R., Reppert, T. R., Summerside, E. M., Yoon, T., \& Ahmed, A. A. (2019). Movement vigor as a reflection of subjective economic utility. Trends in Neurosciences, $x x, 1-24$. https://doi.org/10.1016/j.tins.2019.02.003

Shen, W., Hamilton, S. E., Nathanson, N. M., \& Surmeier, D. J. (2005). Cholinergic Suppression of KCNQ Channel Currents Enhances Excitability of Striatal Medium Spiny Neurons. The Journal of Neuroscience, 25(32), 7449-7458. https://doi.org/10.1523/JNEUROSCI.1381-05.2005

Shen, W., Tian, X., Day, M., Ulrich, S., Tkatch, T., Nathanson, N. M., \& Surmeier, D. J. (2007). Cholinergic modulation of Kir 2 channels selectively elevates dendritic excitability in 
Smalianchuk, I., Jagadisan, U. K., \& Gandhi, N. J. (2018). Instantaneous midbrain control of saccade velocity. Journal of Neuroscience, 38(47), 10156-10167. https://doi.org/10.1523/JNEUROSCI.0962-18.2018

675 Threlfell, S., Clements, M. A., Khodai, T., Pienaar, I. S., Exley, R., \& Cragg, S. J. (2010). Striatal Muscarinic Receptors Promote Activity Dependence of Dopamine Transmission via Distinct Receptor Subtypes on Cholinergic Interneurons in Ventral versus Dorsal Striatum. 30(9), 33983408. https://doi.org/10.1523/JNEUROSCI.5620-09.2010

Timsit-Berthier, M. (1991). Contingent negative variation (CNV) in psychopharmacology. EventRelated Brain Research, EEG Suppl.(42), 142-152.

Walter, W. G., Cooper, R., Aldridge, V. J., McCallum, W. C., \& Winter, A. L. (1964). Contingent negative variation: An electric sign of sensori-motor association and expectancy in the human brain. Nature, 203(4943), 380-384. https://doi.org/10.1038/203380a0

Walton, M. E., \& Bouret, S. (2019). What Is the Relationship between Dopamine and Effort? Trends in Neurosciences, 42(2), 79-91. https://doi.org/10.1016/j.tins.2018.10.001

Wang, K. S., Zegel, M., Molokotos, E., Moran, L. V, Olson, D. P., \& Pizzagalli, D. A. (2020). The acute effects of nicotine on corticostriatal responses to distinct phases of reward processing. Neuropsychopharmacology, 45, 1207-1214. https://doi.org/10.1038/s41386-020-0611-5

Zénon, A., Devesse, S., \& Olivier, E. (2016). Dopamine manipulation affects response vigor independently of opportunity cost. Journal of Neuroscience, 36(37), 9516-9525. https://doi.org/10.1523/JNEUROSCI.4467-15.2016 
bioRxiv preprint doi: https://doi org/10.1101/2021.07.28.454154 $\cdot$ this version posted July 29.2021 . The copyright holder for this preprin (which was not certified by peer review) is the author/funder, who has granted bioRxiv a license to display the preprint in perpetuity. It is made available under aCC-BY 4.0 International license.

\section{Supplementary Information}

695 Statistical tables

Table S1. Linear mixed-effects trial-wise regression outputs for behavioural variables. Each model also included a random effect of participant. RT was log-transformed for this analysis. Significant effects are shown in red.

\begin{tabular}{llrrrr} 
Measure & Term & $\boldsymbol{\beta}$ & $\mathbf{S E}$ & \multicolumn{1}{c}{$\mathbf{t}$} & $\mathbf{p}$ \\
\hline Residual velocity & Incentive & 0.1266 & 0.0073 & 17.4001 & $<.0001$ \\
$\mathbf{( d f = 1 , 1 8 5 7 7 )}$ & Distractor & -0.0158 & 0.0073 & -2.1786 & .0294 \\
& THP & -0.0001 & 0.0073 & -0.0153 & .9878 \\
& Incentive * Distractor & -0.0067 & 0.0073 & -0.9143 & .3605 \\
& Incentive * THP & -0.0216 & 0.0073 & -2.9678 & .0030 \\
& Distractor * THP & 0.0023 & 0.0073 & 0.3152 & .7526 \\
& Incentive * Distractor * THP & 0.0052 & 0.0073 & 0.7158 & .4741 \\
\hline Saccade RT & Incentive & -0.0767 & 0.0059 & -12.9162 & $<.0001$ \\
(df = 1, 18577) & Distractor & 0.0348 & 0.0059 & 5.8549 & $<.0001$ \\
& THP & 0.0244 & 0.0059 & 4.1010 & $<.0001$ \\
& Incentive * Distractor & -0.0035 & 0.0059 & -0.5826 & .5601 \\
& Incentive * THP & 0.0218 & 0.0059 & 3.6723 & .0002 \\
& Distractor * THP & -0.0117 & 0.0059 & -1.9689 & .0490 \\
& Incentive * Distractor * THP & 0.0076 & 0.0059 & 1.2714 & .2036 \\
\hline Distractor pull & Incentive & 0.0023 & 0.0070 & 0.3261 & .7444 \\
(df = 1, 18577) & Distractor & 0.2446 & 0.0070 & 35.0416 & $<.0001$ \\
& THP & 0.0283 & 0.0070 & 4.0570 & $<.0001$ \\
& Incentive * Distractor & 0.0028 & 0.0070 & 0.3982 & .6905 \\
& Incentive * THP & 0.0030 & 0.0070 & 0.4340 & .6643 \\
& Distractor * THP & 0.0226 & 0.0070 & 3.2348 & .0012 \\
& Incentive * Distractor * THP & -0.0039 & 0.0070 & -0.5631 & .5734
\end{tabular}


bioRxiv preprint doi: https://doi.org/10.1101/2021.07.28.454154; this version posted July 29,2021 . The copyright holder for this preprint (which was not certified by peer review) is the author/funder, who has granted bioRxiv a license to display the preprint in perpetuity. It is made available under aCC-BY 4.0 International license.

Table S2. Linear mixed-effects trial-wise regression outputs for P3a and CNV. Significant effects are shown in red.

\begin{tabular}{|c|c|c|c|c|c|}
\hline Measure & Term & $\beta$ & SE & $\mathbf{t}$ & $\mathbf{p}$ \\
\hline \multirow{7}{*}{$\begin{array}{l}\text { P3a } \\
(d f=1,16554)\end{array}$} & Incentive & -0.0187 & 0.0076 & -2.4513 & .0142 \\
\hline & Distractor & -0.0101 & 0.0076 & -1.3319 & .1829 \\
\hline & THP & 0.0013 & 0.0076 & 0.1720 & .8634 \\
\hline & Incentive * Distractor & -0.0040 & 0.0076 & -0.5244 & .6000 \\
\hline & Incentive * THP & -0.0005 & 0.0076 & -0.0643 & .9487 \\
\hline & Distractor * THP & -0.0077 & 0.0076 & -1.0089 & .3130 \\
\hline & Incentive * Distractor * THP & 0.0067 & 0.0076 & 0.8811 & .3783 \\
\hline \multirow{7}{*}{$\begin{array}{l}\text { CNV } \\
(\mathrm{df}=1,16554)\end{array}$} & Incentive & -0.0928 & 0.0075 & -12.3762 & $<.0001$ \\
\hline & Distractor & -0.0032 & 0.0075 & -0.4287 & .6682 \\
\hline & THP & -0.0502 & 0.0075 & -6.7009 & $<.0001$ \\
\hline & Incentive * Distractor & -0.0015 & 0.0075 & -0.2035 & .8388 \\
\hline & Incentive * THP & 0.0172 & 0.0075 & 2.3026 & .0213 \\
\hline & Distractor * THP & -0.0037 & 0.0075 & -0.4966 & .6195 \\
\hline & Incentive * Distractor * THP & -0.0045 & 0.0075 & -0.6069 & .5439 \\
\hline \multirow{7}{*}{$\begin{array}{l}\text { Pre- } \\
\text { preparation } \\
\text { cue } \\
\text { (df }=1,16554)\end{array}$} & Incentive & -0.0006 & 0.0078 & -0.0712 & .9430 \\
\hline & Distractor & 0.0064 & 0.0078 & 0.8186 & .4130 \\
\hline & THP & -0.0597 & 0.0078 & -7.6126 & $<.0001$ \\
\hline & Incentive * Distractor & -0.0039 & 0.0078 & -0.4959 & .6200 \\
\hline & Incentive * THP & -0.0127 & 0.0078 & -1.6256 & .1041 \\
\hline & Distractor * THP & -0.0015 & 0.0078 & -0.1963 & .8444 \\
\hline & Incentive * Distractor * THP & -0.0030 & 0.0078 & -0.3843 & .7008 \\
\hline
\end{tabular}


bioRxiv preprint doi: https://doi.org/10.1101/2021 07 28.454154: this version posted July 29, 2021. The copyright holder for this preprin (which was not certified by peer review) is the author/funder, who has granted bioRxiv a license to display the preprint in perpetuity. It is made available under aCC-BY 4.0 International license.

Table S3. Linear mixed-effects trial-wise regression outputs for the effect of P3a and CNV on each behavioural measure (while controlling for all factors, interactions, and a random effect of participant). P3a did not predict any behavioural measure, while CNV predicted RT and distractor pull. (Bonferroni-corrected threshold: $\alpha=.0056$ ).

\begin{tabular}{|c|c|c|c|c|c|}
\hline ERP & Behaviour & $\beta$ & SE & $\mathbf{t}$ & $\mathbf{p}$ \\
\hline \multirow[t]{3}{*}{ P3a } & Residual velocity & 0.0022 & 0.0075 & 0.2967 & .7667 \\
\hline & RT & 0.0120 & 0.0059 & 2.0313 & .0422 \\
\hline & Distractor pull & 0.0074 & 0.0072 & 1.0225 & .3066 \\
\hline \multirow[t]{3}{*}{ CNV } & Residual velocity & 0.0150 & 0.0076 & 1.9811 & .0476 \\
\hline & RT & 0.1282 & 0.0059 & 21.5854 & $<.0001$ \\
\hline & Distractor pull & 0.0688 & 0.0073 & 9.4145 & $<.0001$ \\
\hline \multirow{3}{*}{$\begin{array}{l}\text { Pre- } \\
\text { preparatio } \\
\text { n cue }\end{array}$} & Residual velocity & -0.0054 & 0.0080 & -0.6758 & .4992 \\
\hline & RT & -0.0030 & 0.0064 & -0.4626 & .6437 \\
\hline & Distractor pull & 0.0100 & 0.0077 & 1.3132 & 1891 \\
\hline
\end{tabular}


bioRxiv preprint doi: https://doi.org/10.1101/2021.07.28.454154; this version posted July 29, 2021. The copyright holder for this preprint (which was not certified by peer review) is the author/funder, who has granted bioRxiv a license to display the preprint in perpetuity. It is made available under aCC-BY 4.0 International license.

\section{Supplementary figures}
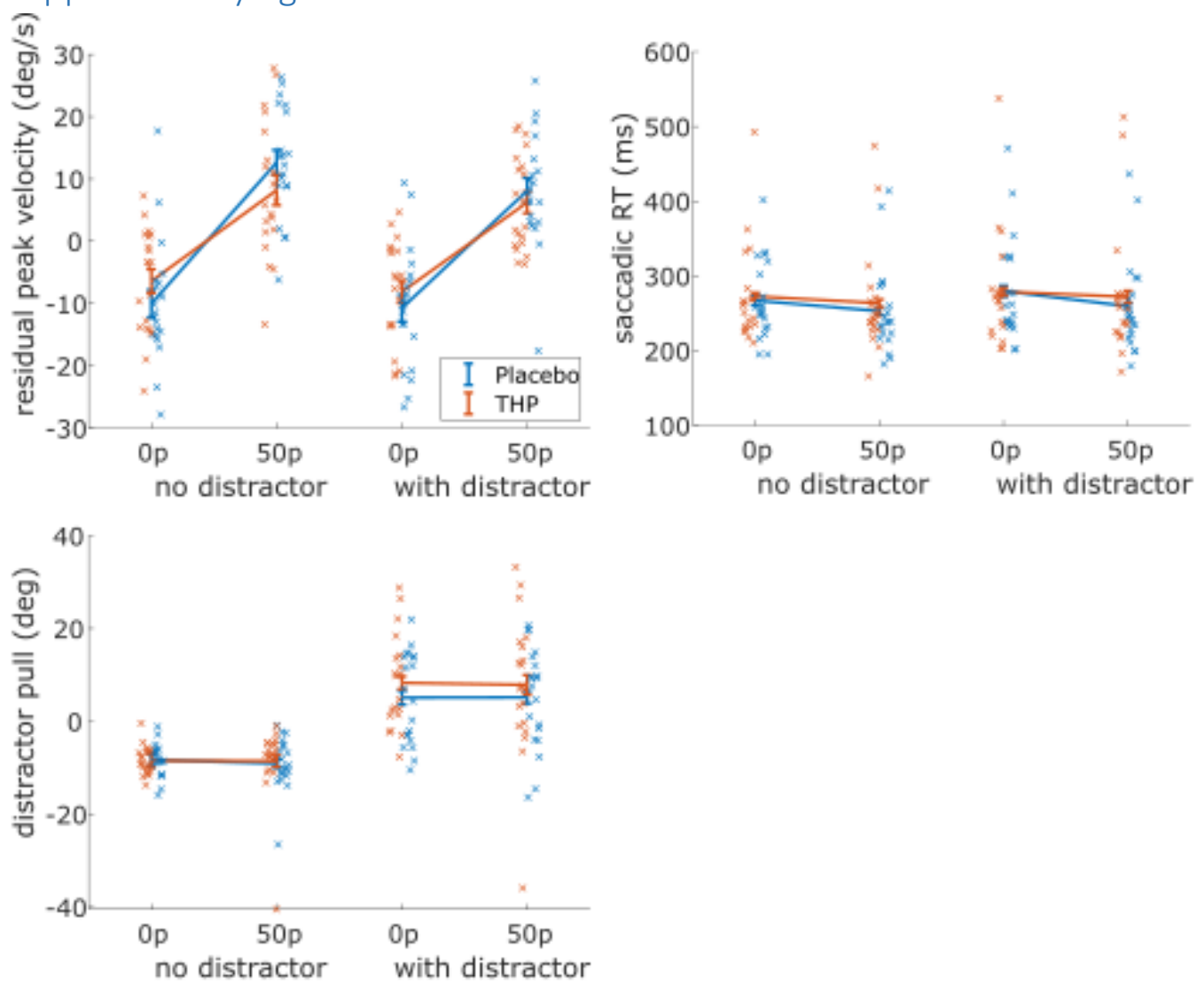

715 Figure S1. Behavioural data with individual means scatter-plotted on top. 
bioRxiv preprint doi: https://doi org/10.1101/2021 07.28.454154; this version posted July 29, 2021. The copyright holder for this preprint (which was not certified by peer review) is the author/funder, who has granted bioRxiv a license to display the preprint in perpetuity. It is made available under aCC-BY 4.0 International license.
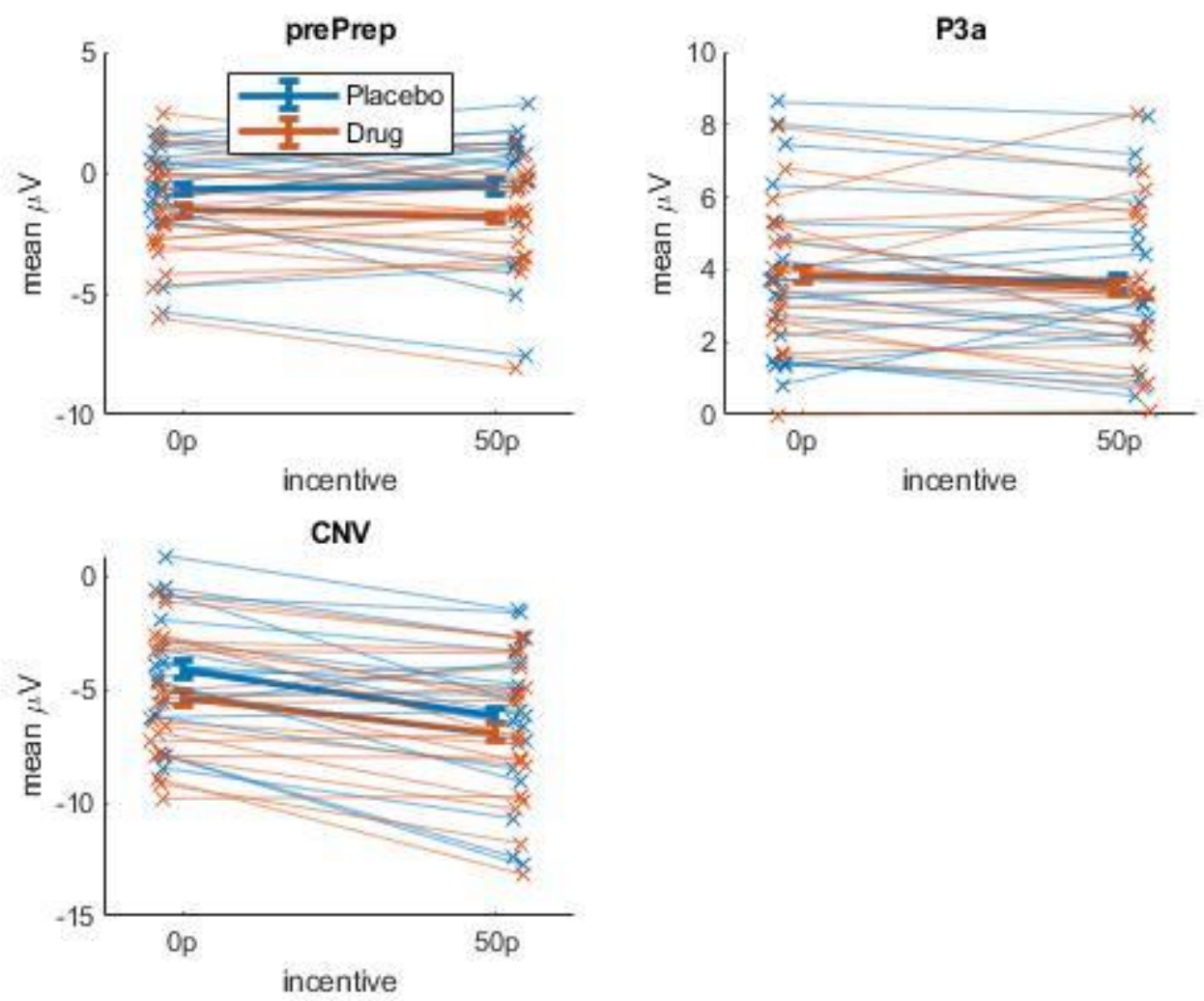

Figure S2. Mean ERP component voltages for each time-window, with the means for each individual person superimposed on top. 
bioRxiv preprint doi: https://doi.org/10.1101/2021.07.28.454154; this version posted July 29, 2021. The copyright holder for this preprint (which was not certified by peer review) is the author/funder, who has granted bioRxiv a license to display the preprint in perpetuity. It is made available under aCC-BY 4.0 International license.

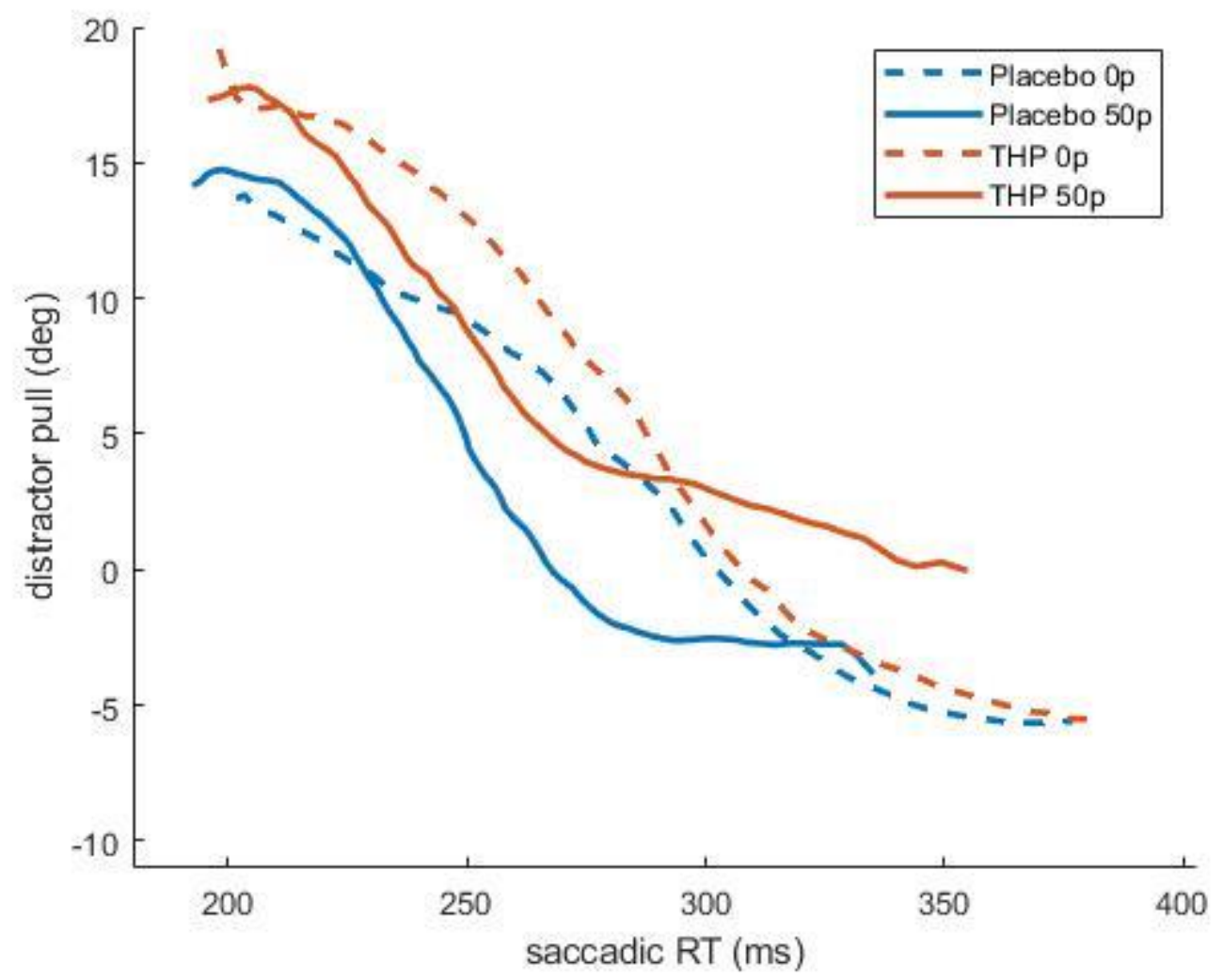

720

Figure S3. Distractor pull as a function of reaction time for all trials with a distractor present, after binning RT into 80 percentile windows for each subject and condition, and plotting mean distractor pull angle for each bin. Distractor pull was greatest for quickest saccades, and incentives sped responses (solid lines shifted leftwards), while THP increased distraction (orange lines shifted upwards) and slowed RT (small rightwards shift). This means that for a given speed, distraction was lessened by incentives. 
bioRxiv preprint doi: https://doi.org/10.1101/2021.07.28.454154; this version posted July 29, 2021. The copyright holder for this preprint (which was not certified by peer review) is the author/funder, who has granted bioRxiv a license to display the preprint in perpetuity. It is made available under aCC-BY 4.0 International license.

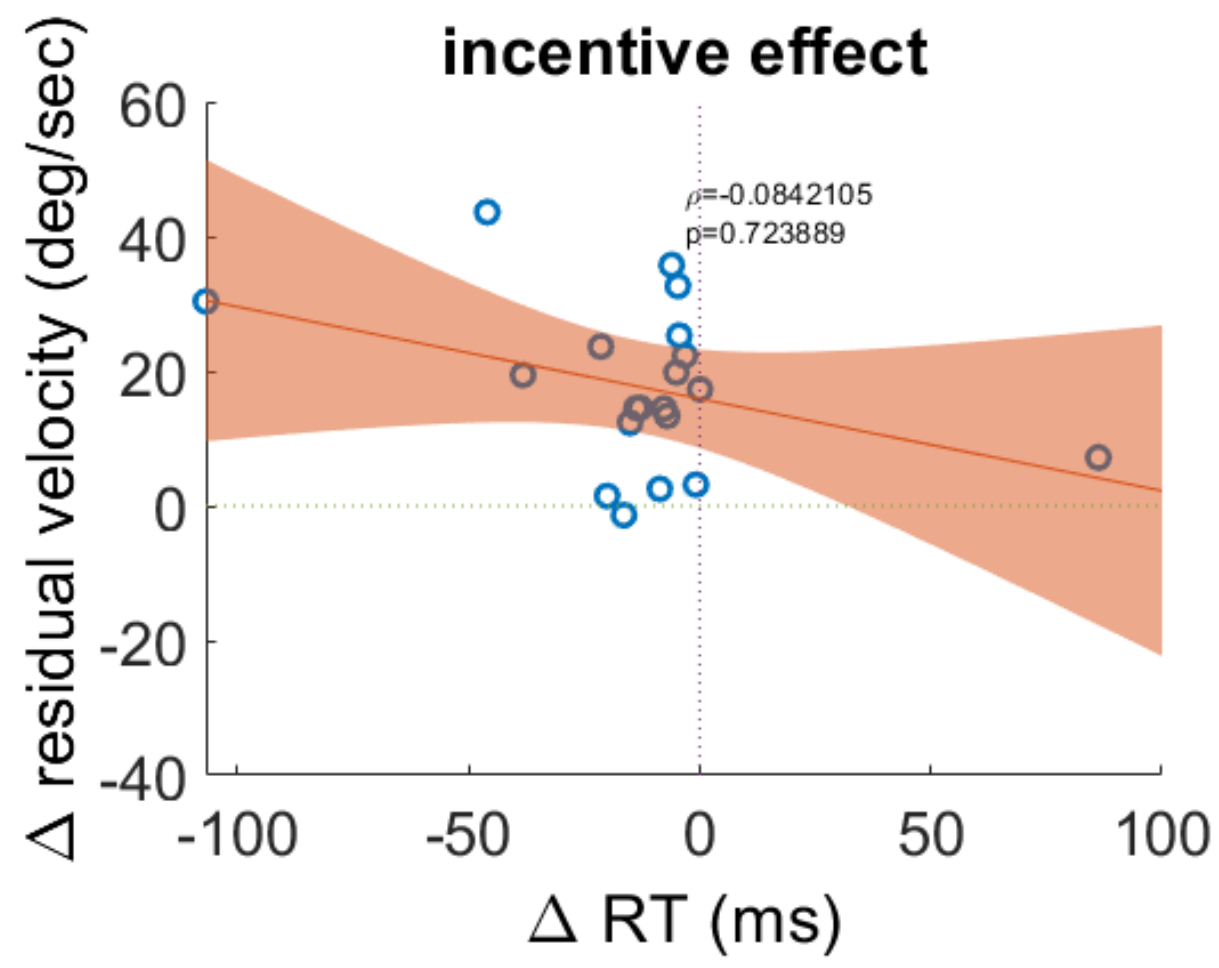

Figure S4. No correlation between the incentive benefits on saccade velocity and RT. Spearman's correlation: $\rho=-.0 .0842, p$ $=.7239$. Each circle is a participant's mean incentive effect (50p-Op) averaged across drug and distractor factors, the 730 orange line shows the linear best fit, and the shading shows the 95\% confidence interval, which includes a horizontal line (i.e. null relationship). 